Revista de análisis cultural N. 16

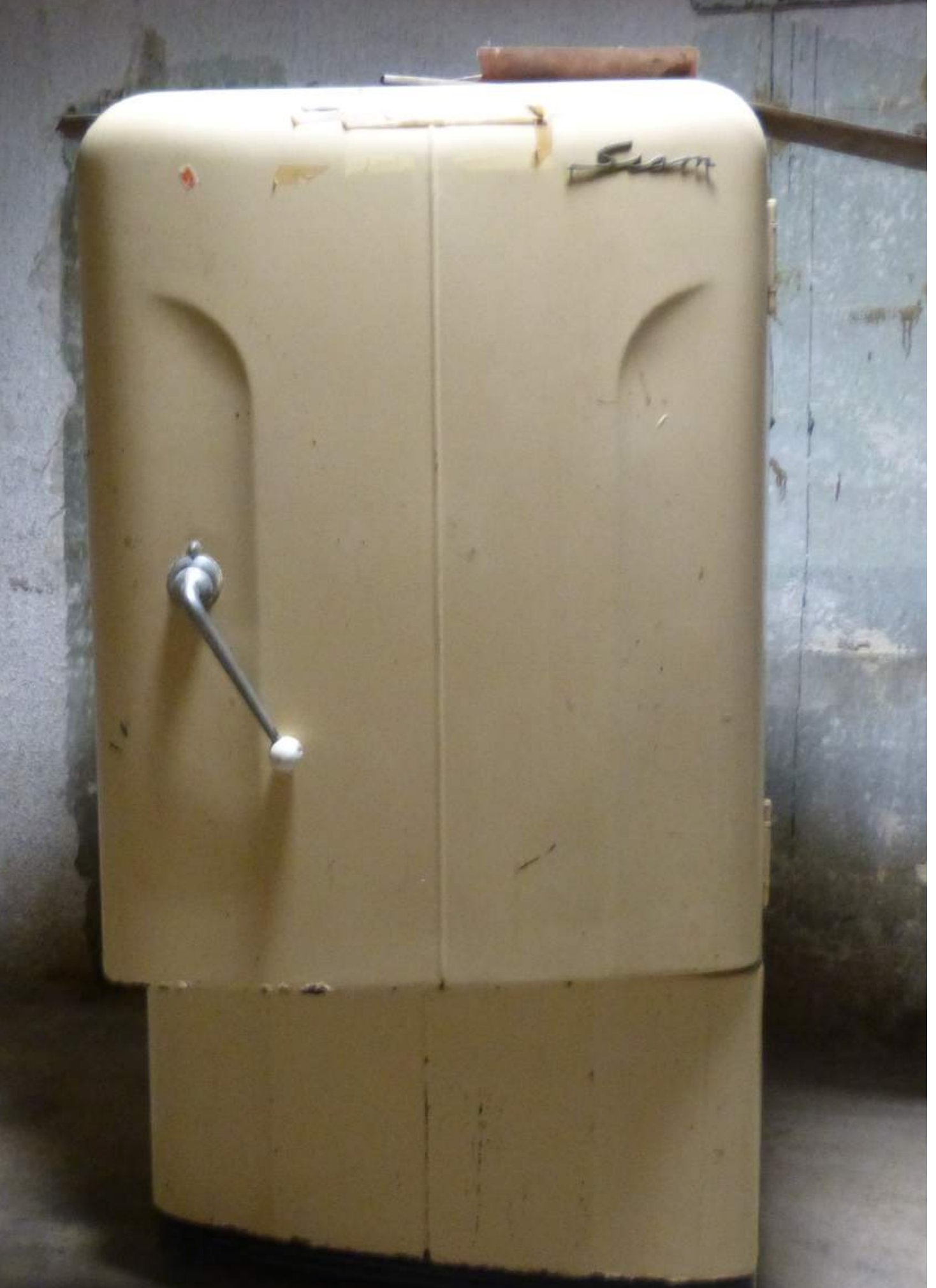

Cosas, objetos, artefactos.

Memorias materiales de la violencia en América Latina

Dossier coord. por Emilia Perassi y Fernando Reati 


\title{
COSAS, OBJETOS, ARTEFACTOS. MEMORIAS MATERIALES DE LA VIOLENCIA EN AMÉRICA LATINA
}

\author{
KAMCHATKA. REVISTA DE ANÁLISIS CULTURAL 16 (2020)
}

Dossier coordinado por EMILIA PERASSI Y FERNANDO REATI

Fernando Reati, Emilia Perassi. Cosas, objetos, artefactos. Memorias materiales de la violencia en América Latina.

EMILIA PERASSI. Objetos-testigo. Fracturas y reconstrucciones del relato identitario.

FERNANDO REATI. La memoria de/en los objetos. Artesanía, dibujos y bordados clandestinos de los presos políticos en la cárcel de Córdoba (Argentina, 1976-1979).

TERESA BASILE. Los objetos en los escenarios de la memoria: aproximaciones teóricas y análisis de ejemplos referidos a los hijos de desaparecidos en Argentina.

LAURA SCARABELLI. Las frazadas en la memoria de la dictadura chilena: el caso de Jorge Montealegre.

EMANUELA Jossa. Cosas, pruebas, indicios: los restos del conflicto armado en el Salvador.

SANDRA LORENZANO. Naufragios.

Imagen de portada:

heladera en habitación vacía en El Olimpo, ex-centro clandestino de detención en Argentina.

Fotografía de Fernando Reati. 


\section{COSAS, PRUEBAS, INDICIOS: LOS RESTOS DEL CONFLICTO ARMADO EN EL SALVADOR}

Things, Evidence, Clues: Remains of the Armed Conflict in El Salvador

EMANUELA JOSSA

UNIVERSITÀ DELLA CALABRIA (ITALIA)

ejossa@unical.it //orcid.org/0000-0002-3700-2283

RECIBIDO: 25 DE MAYO DE 2020

ACEPTADO: 4 DE SEPTIEMBRE DE 2020

RESUMEN: A partir del contexto de impunidad y olvido que se determinó en El Salvador después de la guerra civil (1980-1992), el presente trabajo investiga la presentación y la re-presentación de los restos materiales en el ámbito de la noción de huella como presentificación material de una historia transcurrida pero vigente. Se hace referencia a unos restos (huesos, prendas de vestir, juguetes) que son pruebas procesuales, pero a esta función se añade otra, que implica el nivel afectivo, el trabajo del duelo, la reparación. El trabajo empieza con una breve y necesaria reseña histórica que enlaza la represión de 1932 con la estrategia de la tierra arrasada realizada por las fuerzas armadas en los 80, para luego examinar restos materiales diferentes. Se ponen a dialogar los testimonios, escritos y orales, las instalaciones y las performance artísticas, la ficción, la fotografía, atravesados por el trauma del pasado y las inquietudes del presente. Se investiga cómo la presencia o la evocación de los restos materiales puede vehicular el acceso y la comprensión del pasado en función de una memoria que sea un proceso dinámico y un proyecto de relaciones políticas y culturales diferentes.

PALABRAS CLAVE: El Salvador, conflicto armado, impunidad, memoria material, restos.

ABSTRACT: Drawing on the context of immunity and oblivion in El Salvador following the civil war (1980-1992), the present work intends to investigate the meaning and the function of material remains, by using the notion of trace as the presentification of a history that is past and yet still in force. While this work focuses on remains (bones, clothes, toys) that are juridical evidence, in addition to their juridical function it will also examine another function - one that involves affect, mourning, reparation. The article starts by providing a short but necessary historical synopsis that connects the 1932 repression with the "tierra arrasada" strategy in the 1980 s, during the war. It then moves on to examine different types of material remains, ranging from oral and written testimonies, to works of art, performance, narrative and photography inhabited by past traumas and present concerns. The aim of the article is to explore the ways in which the evocation of material remains enables access to and understanding of the past in the light of a memory that is meant to be both a dynamic process and a project for different political and cultural relations.

KEYWORDS: El Salvador, armed conflict, impunity, material memory, remains. 


\section{- ¿Está la calavera? - \\ pregunté como preguntando por la humanidad de esos restos que me esperaban \\ Marta Dillon, Aparecida}

A lo largo del siglo XX, El Salvador conoció una secuela de gobiernos militares autoritarios, apoyados por la oligarquía terrateniente, que mantuvieron una situación política y económica opresiva e injusta y sostuvieron la marginación de la gran mayoría de la población, pobre y explotada. Durante esa larga etapa, el país vivió dos conflictos armados sobresalientes: el primero en 1932, a un año de la toma de poder por el dictador Maximiliano Hernández Martínez, el segundo en la década de los 80 . Los dos levantamientos ${ }^{1}$ presentan unos parecidos y, por supuesto, muchas diferencias. Lo que interesa resaltar es la marca de un binomio constante: la enormidad de los crímenes cometidos por el ejército gubernamental y la negación o la suplantación de los mismos. Tanto la manipulación de los hechos históricos, como las diferentes formas de imposición del olvido y la omisión de las causas que provocaron las insurrecciones determinaron una fractura entre la historia oficial y la intrahistoria e impidieron, y siguen impidiendo, la implantación de la justicia, en el sentido más amplio del concepto. Desde 1932, hay un conflicto inconcluso, una omisión constante que permite la repetición de la brutalidad de la represión y la conservación de relaciones de fuerza autoritarias e inicuas.

Entonces, se podría afirmar que en El Salvador predomina una escritura de la historia dolorosamente separada de la memoria individual y colectiva. Asimismo, prepondera una disociación entre el poder judicial y las víctimas de los conflictos bélicos y de la violencia política. De ahí la importancia de los testimonios de las víctimas y la necesidad de evidencias materiales que sustenten su narración. En un contexto en que la falta de reconocimiento y justicia sigue dejando abiertas las heridas, los restos materiales de la violencia hubieran podido funcionar como pruebas jurídicas, pero se revelaron casi inútiles por la falta de procesos tanto en 1932 como después de la Ley de Amnistía de 1993.

No obstante, los restos materiales tienen un papel muy importante en el trabajo de la memoria, del duelo y de la petición de justicia. Con el fin de investigar el significado de los residuos, en primer lugar, presentamos una síntesis de los dos principales conflictos ya mencionados, útil para mostrar cómo la ausencia o presencia de los restos tiene repercusiones históricas, jurídicas y emocionales. Luego se profundiza la función de los restos materiales a través de la noción de huella, entendida como presentificación material de una historia transcurrida, pero que sigue siendo dolorosa y vigente, debido a la falta de una verdadera pacificación, a las demandas que han quedado sin respuesta, a la justicia suspendida y a las diferentes interpretaciones de las causas y de las responsabilidades del conflicto. Posteriormente, el análisis se centra en los objetos encontrados en los lugares destruidos, entre las ruinas: las cosas fotografiadas después de una masacre, las prendas de vestir y los juguetes encontrados en las fosas comunes, los huesos tirados en las aldeas devastadas, los utensilios quemados en las casas

\footnotetext{
${ }^{1}$ Como no es necesario para la comprensión del artículo, no se distingue aquí entre insurrección, levantamiento y revolución.
} 
destruidas. Estos restos materiales tienen un papel central en muchas expresiones culturales atravesadas por el trauma del pasado y/o por las inquietudes del presente, relacionadas con la guerra civil. Los ejemplos aquí presentados construyen un entramado denso: el Museo de la palabra y la imagen que recoge, ordena y explica los restos materiales; los testigos que evocan los objetos en textos escritos, en los procesos, en las entrevistas, que acarician un zapato chamuscado y aplastado o muestran una camiseta oscurecida y tiesa; los escritores que ponen al centro de su ficción los vestidos o los juguetes de niños y jóvenes muertos; las performance que tienen lugar entre las ruinas...

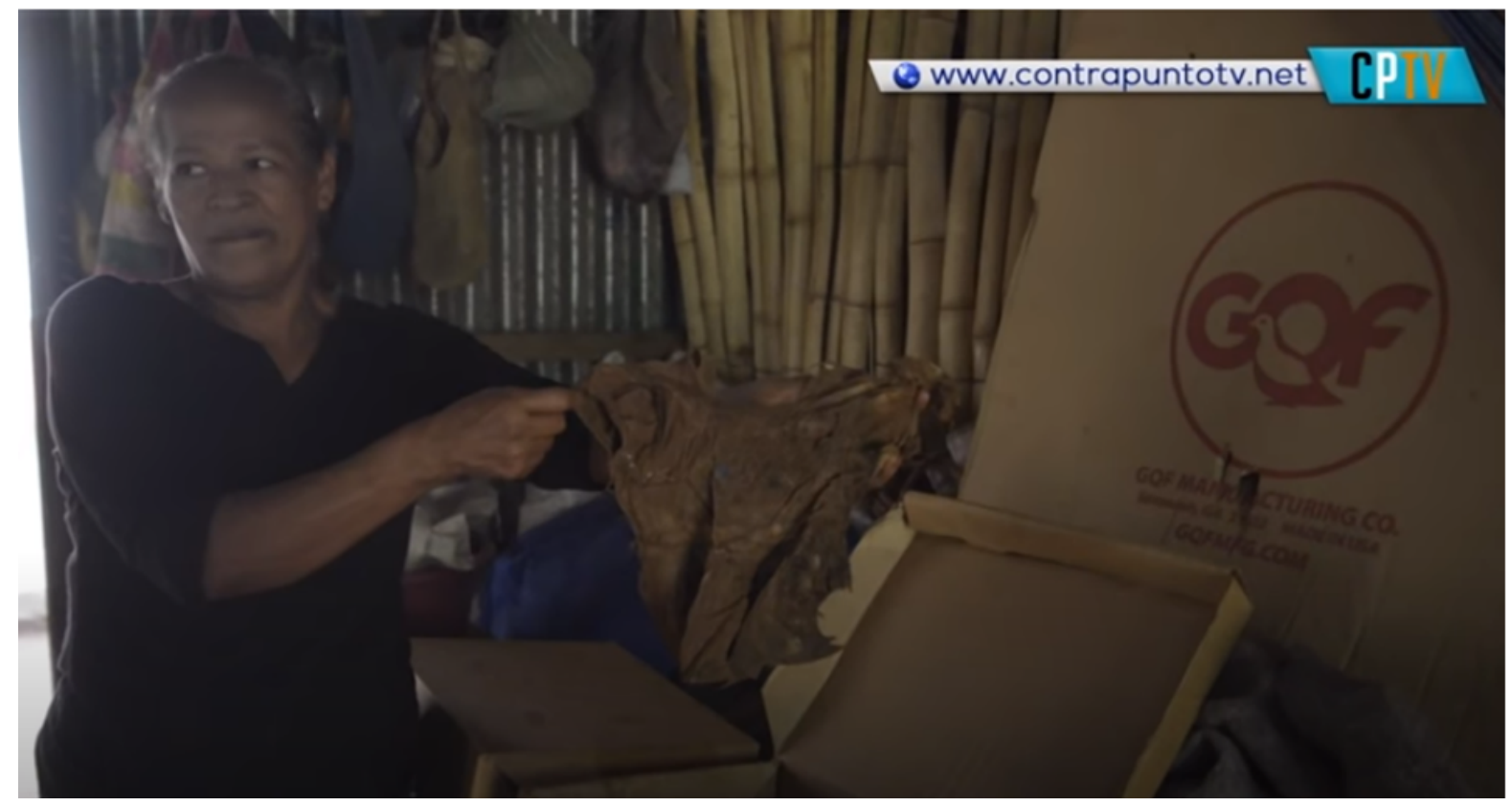

Restos exhumados de un vestido

Imagen del video Exhumaciones en El Mozote: la lenta escritura de la verdad

Estos ejemplos componen una visión general de la relación entre memoria, justicia y reconocimiento (Ricoeur 2004b y 2006) en El Salvador. A partir de su materialidad, los restos confieren un estatus de "existencia verdadera" a la vida y a la muerte de las víctimas. Además, al referirse concretamente a unas vidas cuya dignidad ha sido negada, los restos adquieren una densidad afectiva y a la vez un significado político. En un contexto de olvido impuesto, los restos materiales, como veremos, son signo, efecto y petición y su presentación reitera la demanda de justicia. Estas cosas pueden favorecer el acceso al pasado y luego el paso de la comprensión a la acción, pueden impulsar una memoria activa y una ligazón dinámica entre el pasado y el presente, simbólicamente o metafóricamente expresada en los ejemplos de la conclusión de este trabajo.

\section{BREVE RECORRIDO POR UNA HISTORIA (CASI) SIN RESTOS}

Los hechos ocurridos en 1932 en El Salvador siguen siendo objeto de disputa². Un año tras la toma de poder del general Martínez, los campesinos ladinos y los indígenas, despojados de sus posesiones por la abolición de la propiedad comunal — resultado de la reforma liberal (1881-82)

2 Para una revisión historiográfica ver Vásquez Ruiz Rolando, 2014. Para unos historiadores se trató de un levantamiento campesino de corte marxista, para otros fue una rebelión indígena (Lara Martínez). El rol del PCS (Partido Comunista Salvadoreño) también es objeto de debate. 
- reclamaron la devolución de la tierra y el derecho a la autodeterminación. El Partido Comunista Salvadoreño también participó en la lucha. La fuerza militar reprimió a los rebeldes, justició a los líderes Feliciano Ama y Farabundo Martí y exterminó millares de indígenas y campesinos. Hasta aquí los hechos. Luego, los documentos necesarios para reconstruir los pormenores de la historia se perdieron "convenientemente" (Anderson 2001: 286). La propaganda oficial propuso la imagen de un país dividido en dos: por un lado, un ejército que defendió la nación heroicamente y por el otro una chusma sanguinaria de indígenas y campesinos, salvajes y comunistas, ladrones y asesinos de finqueros inocentes. Los insurrectos, nunca llamados por sus nombres, en la prensa de la época se "transmutan en abstracciones conceptuales, en frases que conjuran ideas extrañas, amenazantes" (Candelairo 2002): anarquía, comunismo, revolución. En esta polarización de la sociedad, se prescindió de las causas de la insurrección y, de manera simple pero tajante, se separaron las vidas que importan de los puros cuerpos biológicos. Se persiguió el mandato fundamental del poder, es decir, como asevera Agamben, la producción del homo sacer, de vidas desnudas privadas de derechos. Esta atávica exclusión fue un legado ineludible para la gestión del conflicto de los 80 .

Como han mostrado Jeffrey Gould y Lauria Santiago (2008: 308-314) esta narración oficial presentó versiones tan poderosas de los acontecimientos que logró reorganizar la memoria misma de los sobrevivientes. Esta manipulación determinó la falta de memoria y de conciencia histórica, en pos de la repetición del pasado. Conocedor de esta estrategia, Roque Dalton se dedicó a fomentar la conciencia histórica de los salvadoreños. En su poema Todos subraya poética y polémicamente el legado de violencia y dolor y la permanencia de las mismas e injustas relaciones de poder: "Todos nacimos medio muertos en 1932/ser salvadoreño es ser medio muerto". La consecuencia política más evidente de las masacres del 32 fue la concentración de riqueza y poder en las manos de unos cuantos terratenientes, apoyados por gobiernos opresivos y autoritarios. De hecho, a lo largo de los años, el poder mantuvo la desigualdad del orden económico y político y sostuvo un permanente estado de excepción que permitió la violencia brutal del estado. En los años 70, las fuerzas armadas gubernamentales reprimieron sistemáticamente a las agrupaciones sindicales, campesinas, religiosas y universitarias que se oponían al poder. Después del fraude electoral de 1972, la represión recrudeció. Las fuerzas armadas intervinieron en la Universidad del Salvador con tanques y helicópteros y capturaron a 800 personas, entre ellas el rector y el director de la Facultad de Medicina. El presidente Arturo Molina decretó el cierre de la Universidad. Fue el primer escalón del incremento progresivo de la violencia de estado. En los últimos años de la década, fue asesinado el sacerdote jesuita Rutilio Grande (1977) y hubo la matanza de 24 estudiantes que habían tomado la catedral de San Salvador (1979). El comienzo de la guerra entre el ejército gubernamental y los guerrilleros agrupados en el Frente Farabundo Martí de Liberación Nacional (FMLN) coincidió con el asesinato de Oscar Romero, arzobispo de San Salvador, por parte de un grupo armado de ultraderecha. Durante los funerales, el ejército disparó contra de la población y la lucha por un cambio político drástico se radicalizó.

El apoyo de los Estados Unidos al ejército gubernamental contribuyó al estallido y luego a la brutalidad de la guerra. De hecho, el conflicto fue marcado por la violencia desmedida de los militares y los paramilitares, responsables de asesinatos selectivos — como la matanza de las 
religiosas norteamericanas, el asesinato de Marianela García y la masacre de Ignacio Ellacuría, otros jesuitas y sus dos colaboradoras en la Universidad Centroamericana José Simeón Cañas (UCA. Los viejos testigos de la represión del 32 experimentaron esta violencia como "el regreso de un trauma reprimido" (Gould y Lauria Santiago 2008: 337).

La reflexión sobre la materialidad de la memoria y sus objetos se enlaza dramáticamente con esas masacres que pertenecen a las operaciones de "tierra arrasada", una estrategia militar de exterminio llevada a cabo como práctica contrainsurgente. Los militares atacaban poblaciones en donde a menudo solo había hombres desarmados, niños, mujeres y ancianos. Violaban a las mujeres, mataban, quemaban las casas, las milpas, arrasaban los graneros y exterminaban a los animales. La estrategia consistía en la destrucción total de comunidades enteras para "quitarle agua al pez", o sea para acabar con las bases de apoyo a la guerrilla. Además, el terror producido por estos operativos provocaba el desplazamiento de la población civil, el abandono de los hogares y los cultivos, permitiendo implícitamente la expropiación de las tierras de los campesinos, la pérdida de toda pertenencia y el cese de una organización social comunitaria. Y, no menos importante, los operativos de la tierra arrasada también garantizaban la destrucción de casi todas las pruebas de las masacres.

Entre 1980 y 1984 hay una lista muy larga de operaciones de tierra arrasada, acompañada por un sinnúmero de muertos y devastaciones. Es el paroxismo señalado por la Comisión de la verdad (2019: 14). La masacre de Santa Lucía; la masacre de más de 50 personas en el cantón El Junquillo; la masacre de Los Platanares; la masacre de La tigra y San Francisco Echeverría con 70 muertos; la masacre del Campanario y la Pita, con 111 víctimas. La masacre de El Mozote, donde el Batallón Atlacatl arrasó ochos caseríos y mató a miles de civiles en tres días. La masacre de El Calabozo, en la que el ejército mató a más de 200 personas que estaban huyendo de otro operativo del batallón Atlacatl. La masacre de Las Aradas, en la que las tropas de la Organización Democrática Nacionalista (ORDEN), apoyadas por la Fuerza Aérea, realizaron un asesinato masivo de hombres desarmados, mujeres y niños que estaban huyendo de la violencia de ejército hacia el río Sumpul. A la otra orilla estaba el ejército de Honduras y la población desplazada se encontró atrapada. Estos ejemplos muestran una violencia premeditada y desmedida en contra de la población civil.

El gobierno no solamente rechazó la responsabilidad del ejército, sino que también negó que las masacres hubieran ocurrido. De esa forma, se profundizó la fractura entre la narración subalterna y el discurso oficial. Exactamente como en 1932, señalo de nuevo, para remarcar la permanencia de una fisura que justamente la amnesia pretende volver insanable. A pesar de las denuncias individuales o realizadas por el FMNL a través de la Radio Venceremos y a través de comunicados de prensa, ni el Gobierno, ni la Fuerza Armada, ni el Poder judicial promovieron investigaciones oficiales acerca de las masacres. Por lo contrario, el presidente Napoleón Duarte definió las matanzas como una "treta de la guerrilla" (Danner 2014: 83). En 1990 Pedro Chicas Romero, que se había escondido en una cueva durante la masacre de El Mozote, presentó una demanda criminal en el juzgado de San Francisco Gotera, acusando al batallón Atlacatl de la masacre de El Mozote. La sobreviviente Rufina Amaya se presentó para testimoniar. El Estado siguió negando los hechos y el único juicio que se estaba realizando prosiguió con mucha lentitud hasta la firma de los Acuerdos de Paz entre el Gobierno y el FMNL en 1992. El Salvador estaba 
devastado y contaba con más de un millón de refugiados y desplazados de las comunidades campesinas, y miles de muertos y desaparecidos, en su gran mayoría civiles. La reconciliación tenía necesariamente que fundamentarse en la justicia, en el reconocimiento de las víctimas y en la persecución de los responsables. Con este fin se constituyó una comisión que investigara los crímenes de guerra. La comisión de la verdad publicó el informe De la locura a la esperanza: la guerra de doce años en El Salvador. Informe de la comisión de la verdad para El Salvador. Las investigaciones mostraron que los militares y los escuadrones de la muerte fueron culpables del $96.3 \%$ de los asesinatos. Pero el informe presenta sólo los «graves hechos de violencia» (1993: 10) con impacto o repercusiones fuertes en la sociedad civil. Basándose en esos criterios, la Comisión investigó dos tipos de casos:

a. Los casos o hechos individuales que, por sus características singulares, conmovieron a la sociedad salvadoreña $\mathrm{y} / \mathrm{o}$ a la sociedad internacional;

b. Una serie de casos individuales de características similares que revelan un patrón sistemático de violencia o maltrato y que, vistos en su conjunto, conmovieron en igual medida a la sociedad salvadoreña, sobre todo por cuanto su objetivo fue impactar por medio de la intimidación a ciertos sectores de esa sociedad. (1993: 19)

Como ya se ha aclarado en otros trabajos (Jossa 2015 y 2019), no se cuestiona el método de la Comisión, sino que se hace constar que la recuperación de la memoria cuenta desde el principio con un vacío, tanto a nivel institucional como a nivel emocional.

A los testimonios recogidos por el informe de la Comisión se sumaron los documentos de la memoria histórica del Archivo de la Oficina de Tutela Legal, fundada por el arzobispo Óscar Romero, mientras que el gobierno ocultó sus archivos, alegando varios pretextos. Impedir el acceso a los archivos permitió repetir el paradigma de la manipulación de 1932: negación de los hechos, disminución del número de las víctimas, manipulación de las causas del conflicto y desvalorización de las demandas de los insurgentes. Además, para fortalecer la trama del olvido, el presidente Alfredo Cristiani, del partido Arena, decretó, inmediatamente después de la publicación del informe, una amnistía general, la Ley de Amnistía General para la Consolidación de la Paz de 1993, con el fin oficial de "alcanzar la reconciliación y reunificación de la familia salvadoreña". Mientras el Informe de la Comisión de la Verdad acababa de proclamar explícitamente la necesidad de la superación de la impunidad, la amnistía decretó el olvido y bloqueó de modo autoritario el proceso de transición. El presidente se refirió de manera instrumental a la "familia salvadoreña" aparentando una unidad que en aquel entonces no podía existir. Al inhabilitar el pasado, el gobierno de Cristiani pretendió cancelar el conflicto político, en nombre de una supuesta reconciliación que solamente quería defender al gobierno y al ejército que lo apoyaba. Para que haya reconciliación es necesario tomar en cuenta a los muertos y sus familiares, con sus derechos vulnerados y sus demandas incumplidas. La intención de la ley no fue hacer justicia, ya que no distingue entre víctimas y perpetradores. El gobierno no afrontó el cuestionamiento del poder hegemónico, todo lo contrario, lo fortaleció y ratificó precisamente la condición subalterna de la mayoría de la población que la revolución quería volcar.

Debido a la amnistía, no hubo procesos, ni indemnizaciones, ni sanciones penales. El gobierno de Arena estableció una relación sumamente vertical con la justicia, ya que asignó a los vulnerados una posición enteramente pasiva. En ausencia de procesos, faltó la motivación para 
escuchar a los que necesitaban contar lo que vieron y sufrieron. Frente a la imposibilidad de celebrar los procesos, en 2009 IDHUCA (Instituto de Derechos Humanos de la Universidad Centro Americana José Simeón Canas) y CONACOVIC (Coordinadora Nacional de Comités de Víctimas de Violaciones de los Derechos Humanos en el Conflicto Armado) crearon el El Tribunal Internacional para la Aplicación de la Justicia Restaurativa. En la audiencia celebrada en Suchitoto en 2010, un testigo dijo: "Quiero perdonar, pero antes necesito saber a quién tengo que perdonar” (Juániz Maya, 2015: 108).

En 1992 el Equipo Argentino de Antropología Forense (EAAP) exhumó los despojos de las víctimas de la masacre de El Mozote. Logró establecer que, de los 143 restos encontrados, sólo 7 eran de adultos y 131 eran menores de 12 años. Todas las balas halladas eran de armas estadounidenses.

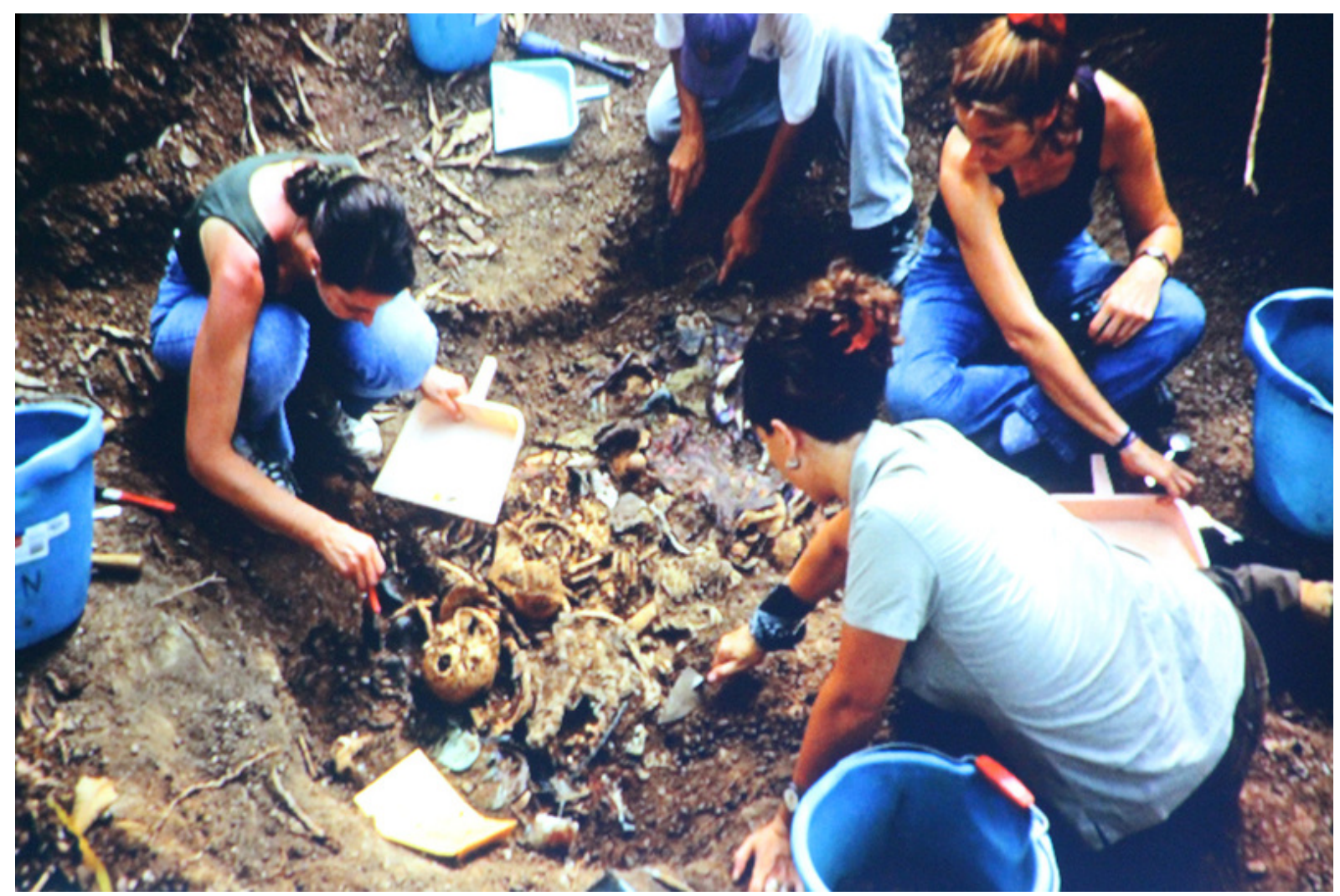

Exhumación realizada por el Equipo Argentino de Antropología Forense

En 2012 la Corte Interamericana de Derechos Humanos estableció la ilegitimidad de la amnistía y declaró al Estado responsable por la violación de los derechos a la vida y a la integridad personal, por la violación de la prohibición de la tortura y otros tratos crueles, inhumanos o degradantes. Entre las disposiciones de la Corte se lee:

-El Estado debe asegurar que la Ley de Amnistía General para la Consolidación de la Paz no vuelva a representar un obstáculo para la investigación de los hechos materia del presente caso ni para la identificación, juzgamiento y eventual sanción de los responsables de los mismos y de otras graves violaciones de derechos humanos similares acontecidas durante el conflicto armado en El Salvador [...] 
-El Estado debe, en un plazo razonable, investigar, por intermedio de las instituciones públicas competentes, la conducta de los funcionarios que obstaculizaron la investigación y permitieron que permaneciera en impunidad $[\ldots]^{3}$

La impunidad, que había frustrado los efectos de estas conclusiones, evadido la denuncia de Pedro Chicas y ratificado la inutilidad de los testimonios de Rufina Amaya, terminó en 2016, cuando la Corte Suprema de Justicia declaró inconstitucional la Ley de Amnistía General. Finalmente, se retomó el juicio penal para la masacre de El Mozote y el Juzgado en San Francisco Gotera abrió un proceso contra 18 militares del Alto Mando de la Fuerza Armada de la época. Muchos testigos ya estaban muertos.

En noviembre de 2019 el juez de Instrucción, Jorge Guzmán requirió al presidente de El Salvador Nayib Bukele (en cuanto comandante general de las fuerzas armadas) el acceso a los archivos militares relacionados con las masacres y por primera vez el gobierno se mostró favorable. En enero de 2020, el juez pidió al Secretario de Estado de Estados Unidos todos los documentos en su posesión sobre la masacre de El Mozote y sobre los militares acusados por el caso $^{4}$. Para los abogados defensores de los militares y del Gobierno, los archivos militares son secretos y no pueden ser revelados porque, como afirmó el abogado José Ángel Pérez Chacón en la audiencia del día 28 de agosto de 2020, la Fuerza Armada protege "bienes superiores de índole colectivo, como la seguridad nacional, la defensa del Estado y la soberanía de El Salvador" (Rauda 2020). Para el juez las informaciones no tienen carácter de reserva porque conciernen graves violaciones a los derechos humanos, y confirmó que va realizar inspecciones a los archivos militares relacionados con la operación "Rescate". Jorge Guzmán agrega: "Toda persona debe estar sometida al cumplimiento de la Constitución y las leyes secundarias, sin importar el cargo que se ocupe. Las decisiones judiciales tienen que cumplirse porque no se toman antojadizamente" (Rauda, 2020). El proceso que se está llevando a cabo en San Francisco Gotera tiene un valor jurídico y simbólico muy importante y representa la posibilidad, por parte de los que sufrieron la injusticia y su olvido, no solamente de tomar la palabra, sino de configurar una visión diferente de la historia y sus ruinas.

\section{SiGNO, EFECTO Y PETICIÓN}

La ocultación de los archivos, todavía muy actual, como muestra el conflicto de los abogados con el juez Guzmán, la amnistía y la falta de soportes materiales, alimentaron la dificultad de elaborar el trauma y de hacer justicia. En el ámbito de diferentes tipologías de

\footnotetext{
${ }^{3}$ En la sentencia también se lee:

- El Estado debe llevar a cabo un levantamiento de la información disponible sobre posibles sitios de inhumación o entierro a los cuales se deberá proteger para su preservación, a fin de que se inicien de manera sistemática y rigurosa, con los recursos humanos y económicos adecuados, las exhumaciones, identificación y, en su caso, entrega de los restos de las personas ejecutadas a sus familiares.

- El Estado debe implementar un programa de desarrollo a favor de las comunidades del caserío El Mozote, del cantón La Joya, de los caseríos Ranchería, Los Toriles y Jocote Amarillo, y del cantón Cerro Pando.

- El Estado debe implementar un programa de atención y tratamiento integral de la salud física, psíquica y psicosocial con carácter permanente.

4 "Bukele insistió en la postura de su Gobierno a favor de la verdad: Cuando la hayamos leído podremos dar una respuesta a eso. Pero tené la total certeza de que sin necesidad de orden judicial hemos estado por reivindicar los derechos de las víctimas del conflicto armado”. Nelson Rauda (2019).
} 
narración de las violencias ocurridas en El Salvador, la permanencia de la aflicción y el deseo de su superación determinan una referencia reiterada a la noción de huella. La huella es la presentificación material de una historia transcurrida pero vigente, es su inmediata evocación. Es la traza que prolonga el tiempo, ya que vincula presente y pasado, presencia y ausencia. Es a partir de esta noción de huella que en las prácticas discursivas sobre la memoria del conflicto armado en El Salvador se establece una conexión muy significativa entre las palabras y los residuos, el lenguaje y los escombros. Se trata de restos materiales que tienen alrededor de 40 años: huesos consumidos, ropa quemada, zapatos desaparejados, juguetes rotos, que son una presencia terriblemente concreta que reenvía a un vacío y a una ausencia terriblemente indeterminados. Por supuesto, el profundo significado de los restos y su conexión con el lenguaje se debe en primer lugar a la función de las cosas como evidencias que puedan corroborar una versión diferente de los hechos, que puedan avalar la perspectiva negada de los damnificados y servir para reclamar justicia. Una función que, desde el comienzo de la violencia en El Salvador, los restos no pudieron desempeñar, incluso cuando se trataba de residuos de disparos, prueba material de que se cometió un delito. Chiyo, autor del testimonio Siete gorriones, a la edad de 8 años encontró a la madre y a la hermana asesinadas por los militares en su casa. Había evidencias: "les habían dado como doce balazos, porque los casquillos de nueve milímetros seguían en el piso" (Vásquez 2012: 39). Pero denunciar a los culpables era una praxis imposible en febrero de 1980.

A esta función jurídica, que solamente desde la declaración de inconstitucionalidad de la Ley de Amnistía puede desempeñarse, se añade otra, que implica el nivel afectivo, el trabajo del duelo y la reparación. Si el testimonio, escrito y oral, es la expresión narrativa y dialógica de la memoria, los restos materiales son las huellas, los signos no verbales de aquella memoria. Una complementariedad parecida entre palabras y cosas se descubre en el arte o en los museos de la memoria, cuando los objetos testimonian con su mutismo o su vacío; o en la narrativa, cuando la huella de las cosas se vuelve la cifra de la comprensión del pasado y de la accesibilidad a los recuerdos. Las cosas del pasado actúan en el presente, no pertenecen completamente al pasado y por esta razón no son inoperantes e inermes. Evidentemente, no son las cosas investidas de nostalgia, pero apaciguadas, del duelo ya elaborado. Estos restos materiales del conflicto armado guardan la memoria de un pasado que, por supuesto, ha sido, pero que no está acabado. Se refieren a lo que ya no es y por eso remiten a una falta, a una ausencia, pero a la vez reclaman el fin de una suspensión, la posibilidad de recomponer la fractura entre el discurso histórico oficial y la memoria íntima.

La ropa vacía pregunta por el cuerpo que la ocupó y denuncia su falta. A la vez, siendo un objeto de uso común, es un signo que remite a una vulnerabilidad compartida y puede operar en función de una memoria activa. Por lo tanto, los restos materiales mantienen con el pasado una relación triple: de significancia, en cuanto signos; de causalidad, en cuanto efecto de un acontecimiento que remite a una historia y a unas vidas negadas; de demanda, en cuanto piden el paso de la privación de los derechos a su afirmación. En síntesis: los restos materiales son signo, efecto y petición. Y buscan el reconocimiento.

La primera etapa del reconocimiento en los casos de violencia es la identificación del cadáver. Sin embargo, en lo que concierne a las masacres en El Salvador, mas bien se trató y se trata de reconocer los restos exhumados después de muchos años: las osamentas, cuya 
procedencia solamente pueden determinar los médicos y los antropologos forenses; las cosas, cuya pertenencia pueden descubrir los familiares. Durante las exhumaciones del 92 en el área de El Mozote, los antropólogos encontraron un caballito de plástico en la mano esquelética de un niño. La antropóloga Mercedes Donetti comentó: "Normalmente podríamos usar esto para identificar a la víctima. Aun después de once años cualquier madre reconocería que esto pertenecía a su hijo. Pero aquí también mataron a todas las madres” (Danner 2014: 29).

En El Salvador, pretender las exhumaciones, obtener la restitución de los despojos fueron y siguen siendo acciones necesarias a nivel íntimo y político. Sirvieron (sirven) para otorgar a los parientes la posibilidad de celebrar las exequias. En 2010 en Arcatao fueron entregados a los familiares los despojos de unas víctimas de la guerra. Comentó una madre: "Fui a Medicina Legal y me dieron el hijo, por voluntad de Dios, verdad... uno se conforma... mirar algo, aunque sean los restitos". Luego agregó "Se consuela uno porque ya no está botado...ya está guardadito y no por allá despreciado".

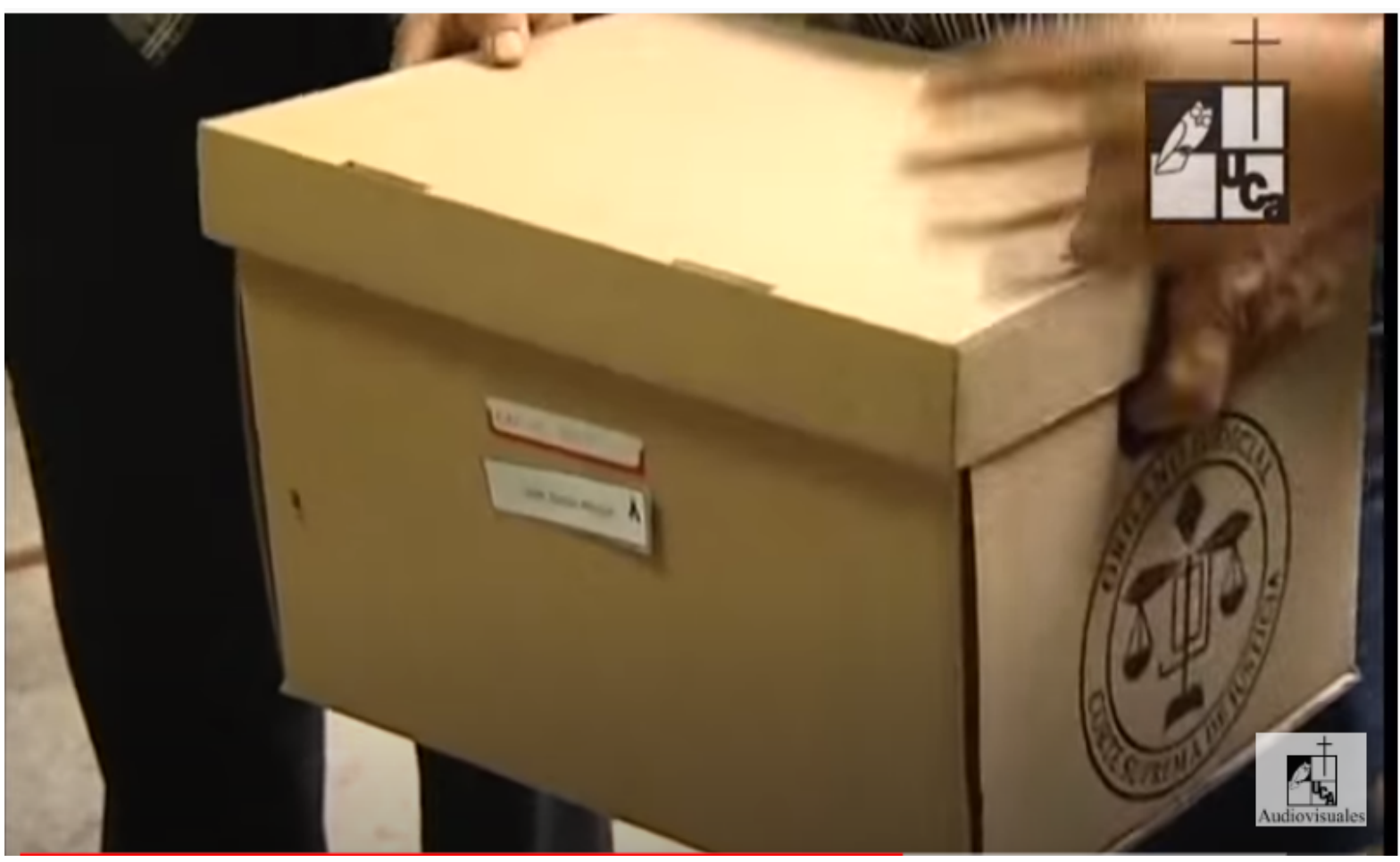

Entrega de una caja con los despojos exhumados en Arcatao Imagen del video Exhumaciones en Arcatao. Justicia pendiente (2010) de

Audiovisuales UCA

La dignificación de las víctimas es el primer paso hacia el esclarecimiento de los hechos y el establecimiento de la justicia. Por este motivo, el reconocimiento adquiere una función política también. No se quiere sufragar una noción redentora de la ley, menos aún en su función de sustento y vehículo de una imagen utópica de una nación pacificada. Los cambios de sentimientos hacia el pasado no implican un cambio social sustantivo ni el cese de la experiencia de injusticia y subordinación. Pero el reconocimiento es el rescate de las puras vidas desnudas puestas fuera de la jurisdicción del estado y la oportunidad de una articulación diferente del 
discurso histórico y de las relaciones sociales. Reconocer y recordar se vuelven así actividades dinámicas y de gran fuerza política. Un punto de partida, no de arribo.

\section{"SIGNOS ALUCINANTES ENVUELVEN LOS SENTIDOS"}

Una de las primeras narraciones públicas de lo que quedaba después de la masacre de El Mozote se debe al testimonio radiofónico de Santiago, integrante del FMNL durante la guerra, fundador y voz de la Radio Venceremos que transmitió desde las montañas de Morazán durante once años. Ahora Santiago (Carlos Henríquez Consalvi) es director del MUPI, Museo de la Palabra y la Imagen en San Salvador, fundado después de los Acuerdos de Paz. La primera actividad pública del Museo fue el lanzamiento en 1996 de la campaña permanente "Contra el caos de la desmemoria", una invitación a participar en la reconstrucción de la memoria con la donación de objetos y documentos relacionados con el conflicto armado.

En su libro La terquedad del izote, Santiago comenta la incredulidad y la turbación que suscitó la llegada de noticias todavía inciertas sobre la masacre de El Mozote:

En la casa de radiocomunicaciones se recibe un mensaje proveniente de Morazán: "El Batallon Atacátl masacró a mil campesinos en varios cantones y caseríos". En un primer momento pensamos que era un error, que no era posible una masacre de tan gigantescas dimensiones. Pero se confirmó el mensaje: son mil los asesinados. (2012: 103)

Cuando los guerrilleros lograron expulsar al ejército que custodiaba la zona, unos diez días después de la supuesta masacre, Santiago y su compañero Servando pudieron llegar a El Mozote para conocer la situación, recoger testimonios y aportar "pruebas contundentes" (2012: 106). Escribe Santiago:

En la medida en que nos acercábamos a El Mozote, signos alucinantes envuelven los sentidos, silencio mortal donde antes hubo murmullos de niños jugando y ancianos que tejían la jarcia. El olor a muerte golpea el olfato. Servando, el combatiente que me acompaña, se tapa la nariz: "los zopes se están comiendo a los muertos" me dice. (2012:107)

Después de esta aprensión inmediata, sigue:

La plaza está desierta, por todas partes hay un desorden de platos rotos, escapularios, sombreros de paja, papales y trozos de ropa ensangrentada. Saco la cámara de la mochila, y fotografío un solitario triciclo infantil en medio de la calle que me simboliza toda la intensidad de la tragedia. Entramos a la Iglesia micrófono en mano voy describiendo la escena. Desolación, bancas destrozadas, vírgenes agujereadas, un santo sin cabeza, las paredes pasconeadas por las ametralladoras. Esparcidos por el suelo: zapatos, cédulas de identidad, muñecas, novenarios, un daguerrotipo, peinetas, biberones, sostenes y calzones rotos. (2012: 107) 


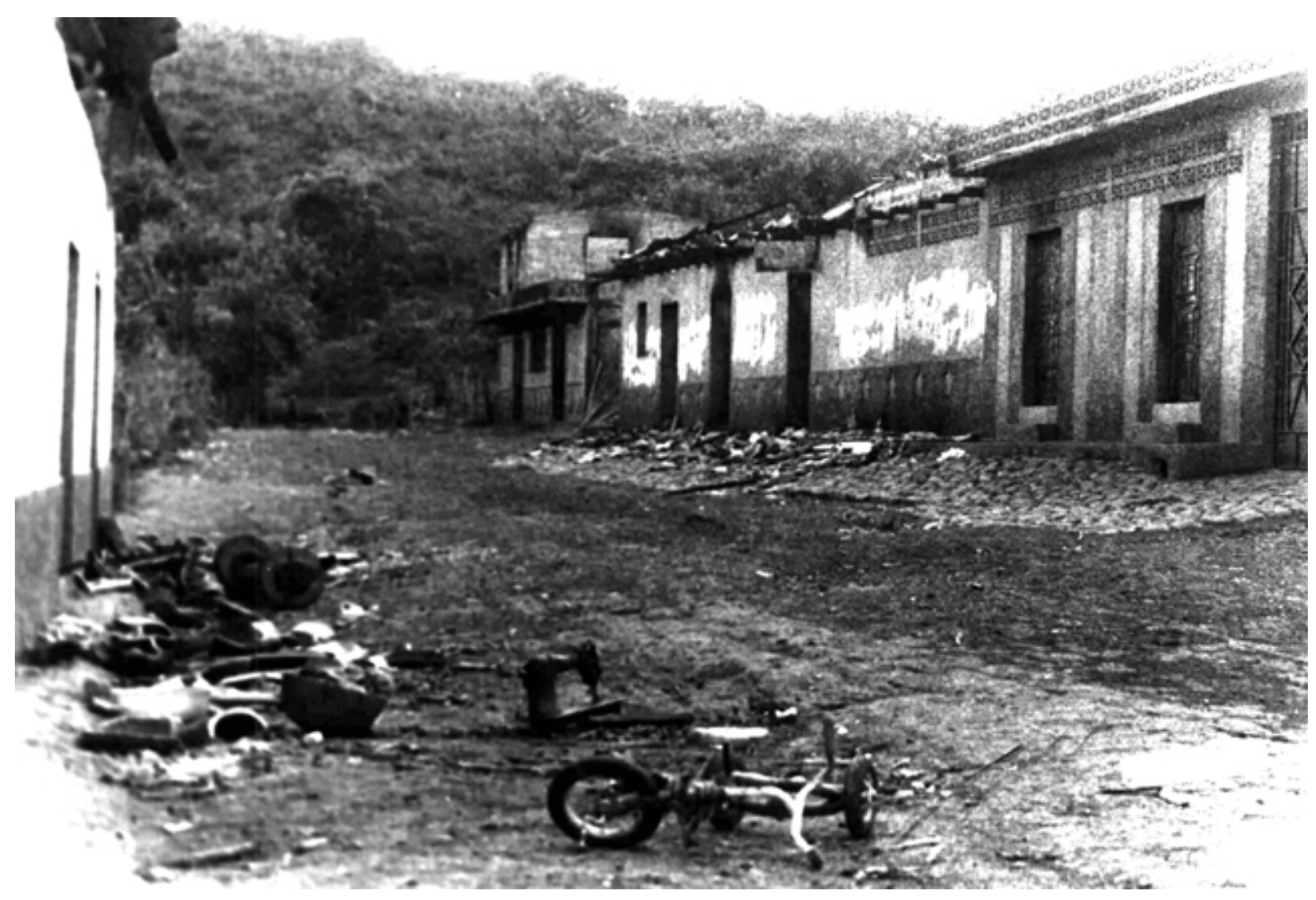

El Mozote después de la masacre, diciembre de 1981.

Archivo Museo de la Palabra y la Imagen

La descripción hecha por Santiago, testigo de la escena de desolación, se fundamenta en "los signos alucinantes". Los sentidos (oído, olfato, luego vista) perciben una realidad trágicamente concreta que enseguida se vuelve signo. El primer signo alucinante es el silencio mortal contrapuesto a las voces de los niños que antes jugaban y a los ruidos de los adultos que antes trabajaban. Luego, él hace un inventario de los restos, de las cosas que remiten al destrozo de unas vidas brutalmente interrumpidas. Frente al sitio de la matanza, la percepción sensorial de Santiago, acompañada por la aflicción, se transforma enseguida en entendimiento. En su testimonio se mezclan descubrimiento, reconocimiento y una fuerte emoción. Su ver, oler, oír, movidos por los datos sensibles, captan de inmediato la dimensión de la tragedia. Los escombros, la ropa tirada, las botas de plástico, la bicicleta abatida, la muñeca sin cabeza permiten una aprehensión instantánea. Las cosas se dan en su privación de vida, en la forma del abandono, son silencio y ausencia. Santiago y Servando las captan a través del olfato (olor a muerte, Servando se tapa la nariz). Luego, a través de la vista de las cosas, cuidadosamente enumeradas en el texto, se pasa al reconocimiento de la situación: la masacre de civiles no fue (solamente) una locura 5 , sino parte de un proyecto político y militar. La escena de El Mozote destruido patentiza la estrategia de la tierra arrasada y reclama justicia. Me atrevo a pensar que las "gigantescas dimensiones" de las que habla Santiago hubieran podido implicar hasta la inversión del "onus probandi" en los procesos que solamente ahora se empiezan a celebrar. Pues considero los escombros y los restos

\footnotetext{
5 Como sugiere el título del Informe de la Comisión de la Verdad: De la locura a la esperanza: la guerra de doce años en El Salvador.
} 
materiales pruebas contundentes de una experiencia que, por otra parte, en lo íntimo, no necesita de pruebas, sino tan solo de restos.

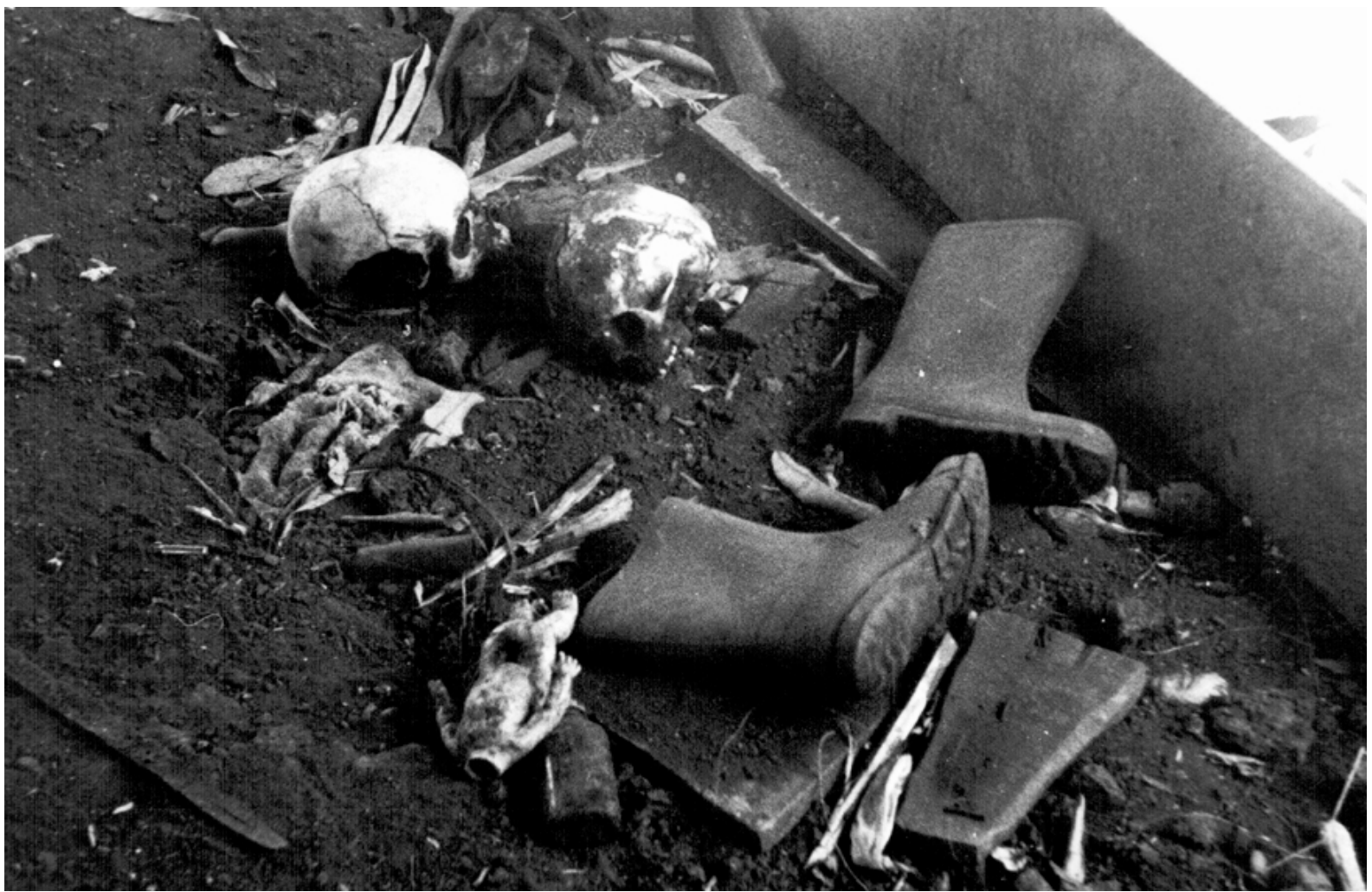

El Mozote después de la masacre, diciembre de 1981.

Archivo Museo de la Palabra y la Imagen

Las cosas esparcidas en las fotos de Santiago son huella y luego signo, efecto y petición. A pesar de estar fundamentadas en el pasado, en estas cosas no hay fijeza sino duración. La continuación en el presente se debe a la actualidad de la demanda de estas cosas de hacerse cargo de la injusticia que implican. Por esta razón Santiago no colecciona restos arqueológicos, sino que transforma la memoria en un proyecto, promueve la justicia y el reconocimiento. Su finalidad es "crear y socializar publicaciones, foros y exposiciones dedicados a impulsar conocimiento, generar debate e incitar participación ciudadana, en la búsqueda de soluciones a las amenazas y debilidades que nuestra sociedad enfrenta". En el MUPI la memoria es transmisión y construcción.

\section{CAMISAS, VESTIDOS, JUGUETES}

La primera publicación del Museo de la palabra y de la imagen fue Luciérnagas de El Mozote (1996). El libro empieza por el testimonio de Rufina Amaya, sobreviviente de la masacre:

Me llamo Rufina Amaya, nací en el cantón La Guacamaya del caserío El Mozote. El once de diciembre del año 1981 llegó una gran cantidad de soldados del ejército. Entraron como a las seis de la tarde y nos encerraron. A otros los sacaron de las casas y los tendieron en las calles boca abajo, incluso a los niños, y les quitaron todo. (15) 
Los testimonios de Rufina Amaya siempre empiezan por la declaración de su nombre y de su lugar de nacimiento, un acto tan simple y necesario que afirma su dignidad y la sitúa espacial e históricamente, aseverando su pertenencia a la humanidad y a la historia. Su presentación es la primera petición de reconocimiento frente al poder que sometió y expulsó a los campesinos del ámbito del derecho.

Rufina Amaya repitió muchas veces los pormenores de la masacre en la que perdió a casi toda su familia. La operación duró tres días: primero ametrallaron a los hombres, luego apresaron a las mujeres, muchas fueron violadas y luego ejecutadas. Rufina quedó última de una larga fila de mujeres, los militares le quitaron la niña de ocho meses de los brazos. Logró esconderse en un matorral, detrás de unas plantas de manzano rosa y desde su escondite, pudo escuchar el llanto y los gritos de los niños: "Mamá nos están matando, mamá, nos están ahorcando, mamá nos están metiendo el cuchillo" (17). Las voces de estos niños remiten concreta y dramáticamente al paradigma primario de la condición vulnerable e inerme, invocan la cura y la protección que la madre no puede otorgarles. Toda la masacre es "una escena desequilibrada por una violencia unilateral" (Cavarero 2009: 59).

Rufina recuerda que tenía un vestido blanco que se destruyó durante la huida. Quedó desnuda y se cubrió con unas prendas que luego encontró en una casita. Así la encontraron, casi enloquecida, después de siete días de terror, llanto y hambre. Cuando se repuso un poco, después de unos quince días, Rufina volvió a su pueblo para buscar a sus hijos: "Vimos las cabezas y los cadáveres quemados. No se reconocían. [...] Quería hallar a mis niños y solo encontré las camisas todas quemadas" (19).

Las prendas de vestir, marcadas por el cuidado y por la cotidianidad de los cuerpos destrozados, son restos materiales dramáticamente investidos ontológicamente. Si la memoria es también el compromiso de darle un sentido a las experiencias, para Rufina el único sentido posible fue asumir la tarea de combatir en contra del olvido y de la impunidad: "Siento un poco de temor al hablar de todo esto, pero al mismo tiempo reflexiono que mis hijos murieron inocentemente. ¿por qué voy a sentir miedo de decir la verdad? Ha sido una realidad lo que han hecho y tenemos que ser fuertes para decirlo" (20).

La fotógrafa norteamericana Susan Meiselas tomó unas de las primeras fotos de la masacre ${ }^{6}$. Fotografió también a Rufina, sentada en el pasto, con un delantal blanco sobre el vestido. Rufina no vuelve los ojos hacia el objetivo. Está ensimismada, la mirada perdida.

\footnotetext{
${ }^{6}$ No se puede abordar aquí la cuestión de las fotografías del horror, ni profundizar la relación entre lo real y su representación en la fotografía. Se remite a Sontag (2003), que rescata el valor ético de la documentación visual de las masacres y a Baudrillard (1978) que remarca la transformación de los hechos en espectáculo.
} 


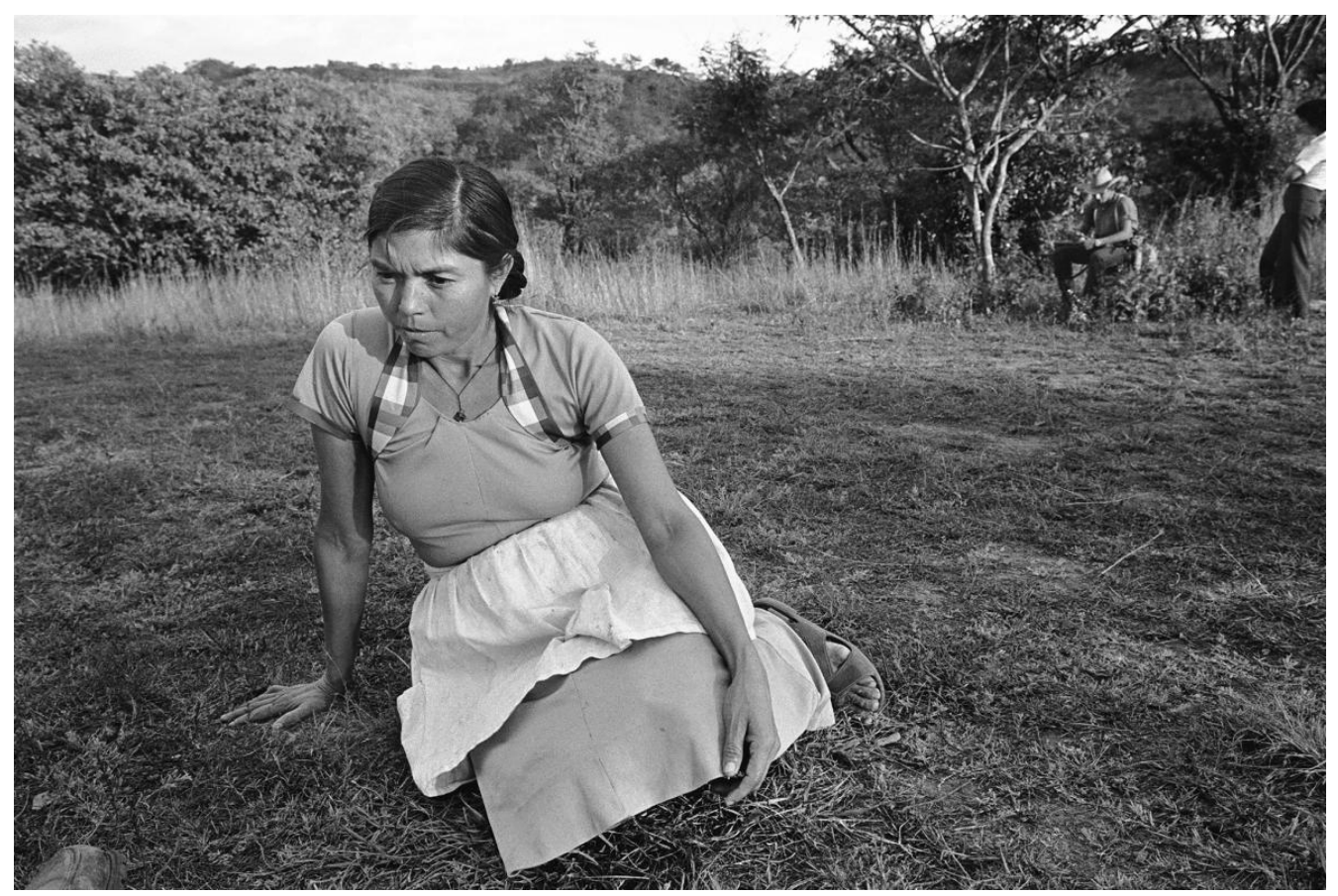

Rufina Anaya, foto de Susan Meiselas

La artista salvadoreña Beatriz Cortez en 2014 retomó la fotografia de Meiselas para la instalación Armadura para Rufina Amaya. El espectador escucha un sonido que repite los nombres de las víctimas de El Mozote y mira la reproducción en acero del vestido y el delantal de Rufina Amaya. La permanencia contra el olvido impuesto es de nuevo un vestido, casi armadura, corazón/coraza de una inolvidable guerrera.

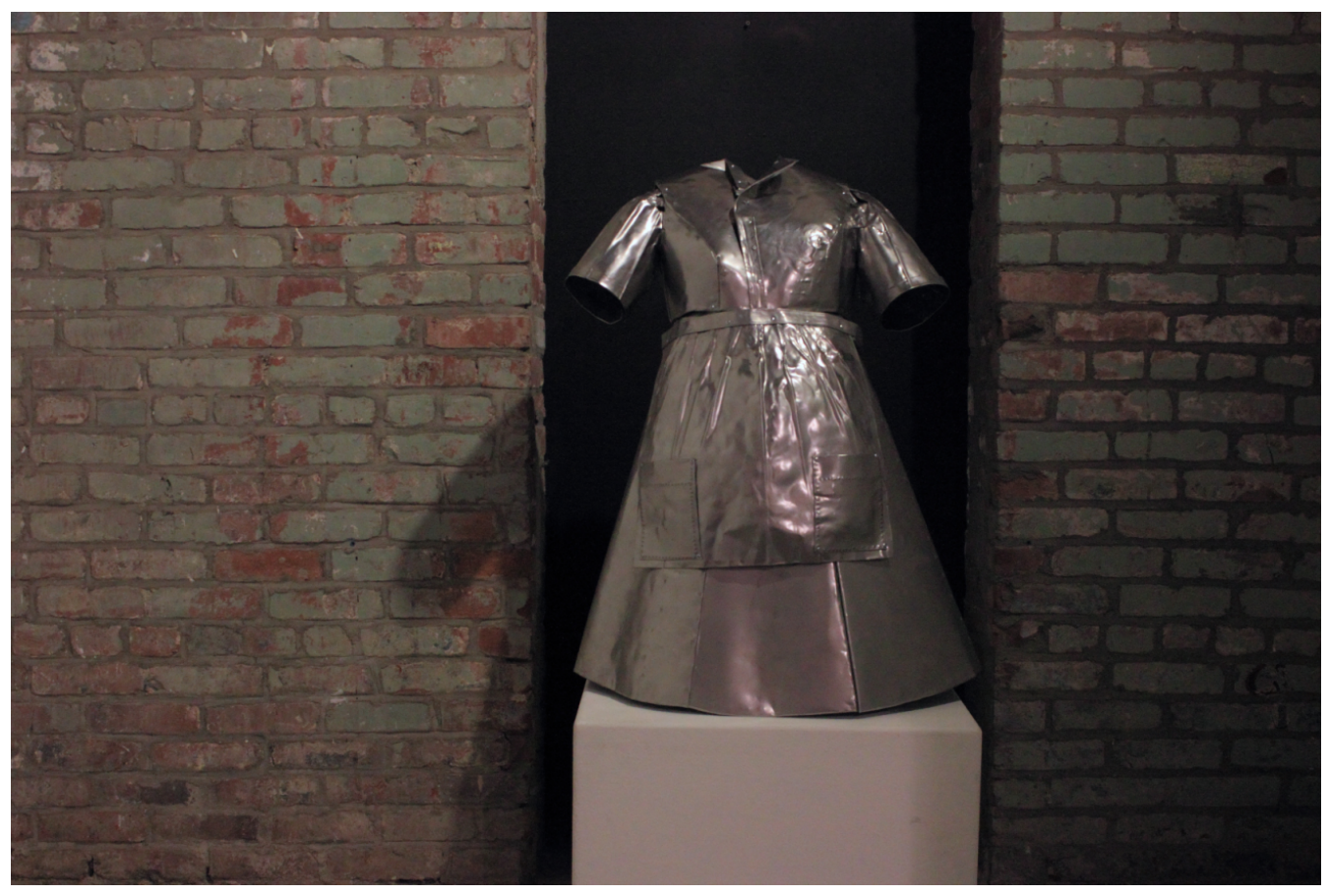

Armadura para Rufina Amaya de Beatriz Cortez 
La amnistía alimentó la dificultad de procesar el trauma y nutrió tanto la necesidad de recoger los testimonios como la de testimoniar en espacios alternativos. A lo largo de los años, el MUPI archivó muchos documentos del conflicto armado y grabó y editó muchos testimonios. Entre otros, el ya mencionado Siete gorriones de Chiyo, Ventana abierta y, en la revista "Trasmallo", una selección de las entrevistas hechas por Kate Kenealy a unas mujeres que sufrieron la violencia de los militares durante la guerra.

Chiyo era un niño de diez años cuando llegó con los guerrilleros a El Mozote, un mes después de la masacre. En su testimonio, describe los escombros y las cosas desamparadas con angustia y ternura:

Solo quedaban ruinas de casas, con las tejas quebradas, las columnas ahumada, los techos y las paredes derrumbados. Habían volado la iglesia para que las paredes cayeran sobre los niños muertos. Dentro y alrededor de las casas se veían juguetes aventados, los cuadernos de los niños tirados, todo a la deriva, a la intemperie. (107)

Con otros niños iba a buscar fruta en los alrededores: "encontrábamos huesos y distinguíamos los de mujeres por los vestidos, y los de los ancianos, por los zapatos o por las hebillas de los cinturones que eran típicas de la ropa de viejo. Trabados sobre los alambrados, o tirados por allí, encontrábamos vestidos de mujer" (107).

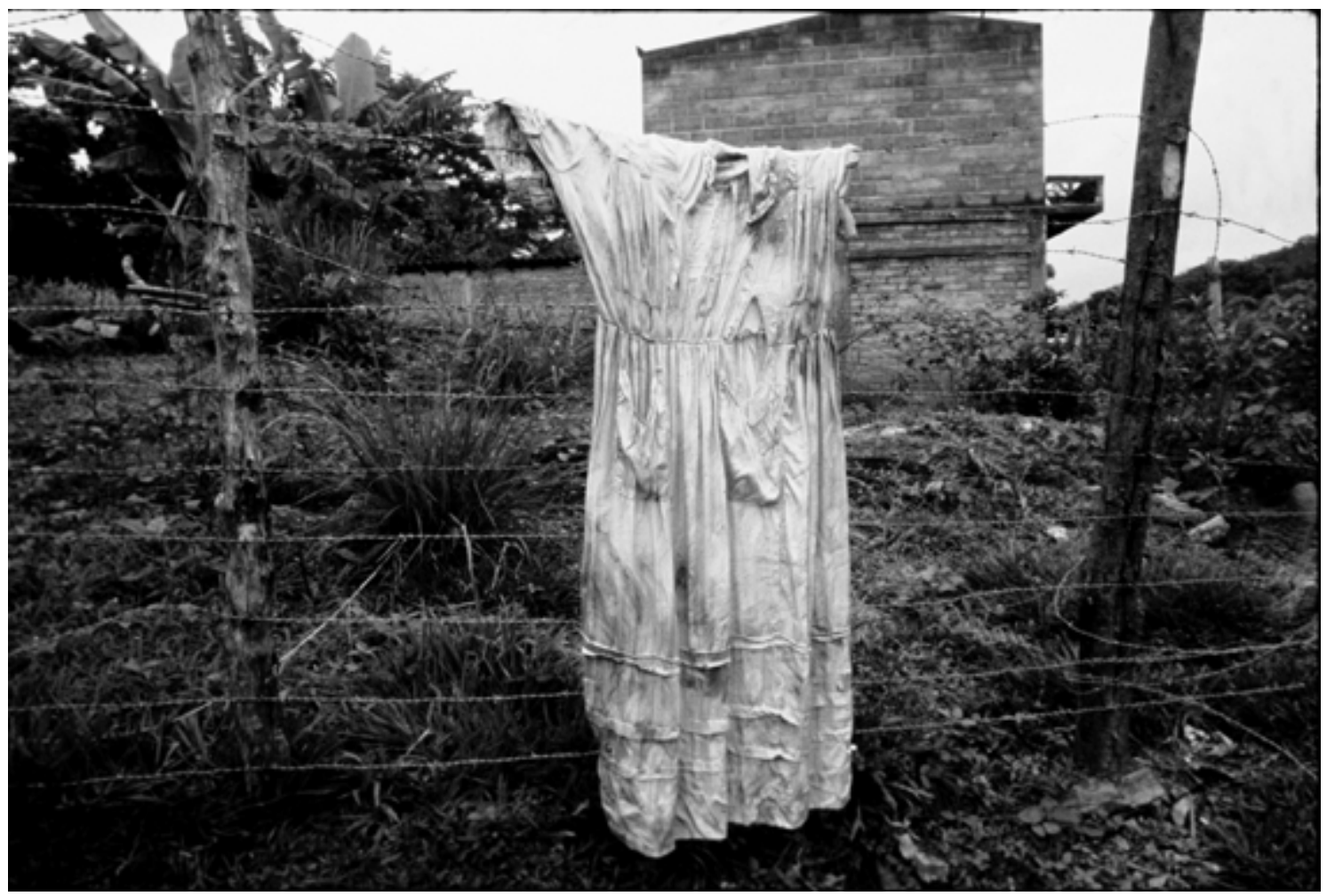

El Mozote después de la masacre, diciembre 1981.

Archivo Museo de la Palabra y la Imagen

Los testimonios recogidos por el MUPI muestran como el pasado irresuelto sigue afectando al presente. En las palabras de muchos testigos, la memoria traumatizada sigue invistiendo las escenas del pasado de una carga emocional intensa que busca la comprensión del 
oyente o del lector. La intención no es romantizar la memoria, sino impugnarla. En las citas a seguir, dos mujeres hablan de la masacre de El Mozote, de la cual fueron testigos desde la distancia. Ambas se refieren primero a su percepción sensorial del acontecimiento. La vista flaquea, prevalecen el oído y el olfato:

Ya oíamos los aviones, volando aquí en El Mozote. Ya cuando era como las once de la mañana ya se miraba la gran humazón jde toditos los colores! Venía un norte y este norte llegaba a un cerro donde estábamos nosotros y sentía el gran olor de carne asada. Nosotros sentíamos el gran olor de carne asada porque estaban quemando toda la gente acá en el Mozote (Crecencia). (Kenealy 2009: 10)

Se fueron para el Mozote y nosotros quedamos. Allá fueron tres días de tirasón. Como era en el verano les daban fuego a los montes. Vimos la humasón y oímos el ruido. A cada rato aquella disparasón, como era una sola reventasón de maicillo. Y había silencio cuando ya fue el 13 de diciembre de 1981. Calmada ya. No oía nada, nada. Solo silencio, un silencio profundo (Nilda). (Kenealy 2009: 25)

Ante la experiencia, destaca la asimetría entre los límites de la capacidad lingüística de nombrar y la consistencia de las impresiones sensoriales. La palabra ordena, vuelve al presente y pone de manifiesto los acontecimientos y los afectos residuales del trauma. El olor a carne asada es un recuerdo olfativo tan certero y fehaciente, pero a la vez tan absurdo que Crecencia debe agregar una explicación: "Nosotros sentíamos el gran olor de carne asada porque estaban quemando toda la gente acá en el Mozote". Al tratarse de situaciones inhumanas no compartidas en la vida ordinaria, la comprensión resulta afectada, en cuanto, como dice Ricoeur "la comprensión se edificó sobre las bases del sentido de la semejanza humana en el plano de las situaciones, los pensamientos, de los sentimientos, las acciones" (2004: 229).

La referencia al silencio, repetida tres veces en el testimonio de Nilda, se contrapone a los ruidos del pueblo con vida, precedentes al estallido de la violencia, ya mencionados por Santiago y muy presentes también en los recuerdos de Chiyo: "el sonido de los trompos" (2012: 27), "el bullicio de los niños se confundía con el de tanto pájaro que había en el cantón, y la alegría de estar allí comiendo guayabas" (25). En las palabras de Nilda, la alternancia entre el estrépito de la "disparasón" y el silencio, entre el ruido y la nada, revela la lógica del exterminio: acabar con todo. Chiyo, para describir la desolación de Los Toriles y de la Chumpa, se refiere de nuevo al silencio y al desamparo de las cosas: "habían matado a la gente casa por casa. Se veía todas las cosas abandonadas, desoladas, sin una voz, sin nada más que la soledad del lugar” (2012: 108).

Recuerda María Josefina Chicas que en 1980 tuvo que dejar su pueblo, Torola, en Morazán, debido a la violencia del ejército: "cuando regresamos a la casa no encontramos nada, todo estaba pura ceniza, el maíz, todo. Los animales estaban muertos. Nos pusimos a llorar" (Sánchez Chicas, 2017: 251). Movidos por el miedo o la esperanza, antes de abandonar sus hogares, unos campesinos desplazados escondieron sus cosas. Cuenta Chiyo: "mi papá empezó a enterrar cosas, los azadones, el arado, las barras, la piedra de moler, el molino para maíz. [...] dentro de unos botes, enterró algo de dinero pensando que talvez podríamos regresar pronto" (2012: 49).

Muchas de las mujeres entrevistadas por Kate Kenealy muestran una evidencia inmediata, a través de la enumeración de vidas humanas, animales y cosas destrozados: la lógica de aniquilación. 
Si hubiéramos pasado por el desvío, nos hubieran matado porque ya venían matando todito, todito: gallinas, chucos, chanchos, vacas, todito. (Crescencia) (Kenealy 2009: 10)

Nuestra casa era como un rancho indígena con zacate, con madera. Recuerdo que la guardia fue allá para botar el maíz al piso, los frijoles, todo, todo, le han dado vuelta a la casa, y han hecho un destrozo... (Arely) (Kenealy 2009: 27)

En esta comunidad [San Vicente] mataron como a doscientas veinte personas. Fue terrible. (...) allí mataron a mujeres embarazadas, les abrieron la panza y les sacaron sus bebés. Metían a la gente en unos ranchitos y ponían un poquito de gasolina y quemaban a la gente allí, viva. Mataron cerdos, mataron vacas, mataron todo lo que había con vida (Arely) (Kenealy 2009: 28)

¡Cada cinco días, cada ocho, cada quince días, llegaban a quemar casas, a matar a gente, a matar gallinas, a matar cuches, a matar vacas! No iban a dejar ni un alma en los cantones, en las aldeas, en los municipios. De parte del gobierno que planteaba esta guerra, la decisión era terminar con la gente pobre (Teodora) (Kenealy 2009: 20)

La materialidad de los objetos y de las escenas de violencia, su insistida percepción sensorial, lidian con la inmaterialidad del recuerdo a través de metáforas y comparaciones. Dice Dimas Hernández: "A la gente la mataron un día en la tarde y en la mañana fuimos a ver. Eran un montón de muertos, como ver una parva de leña desordenada" (Sánchez Chicas, 2017: 260).

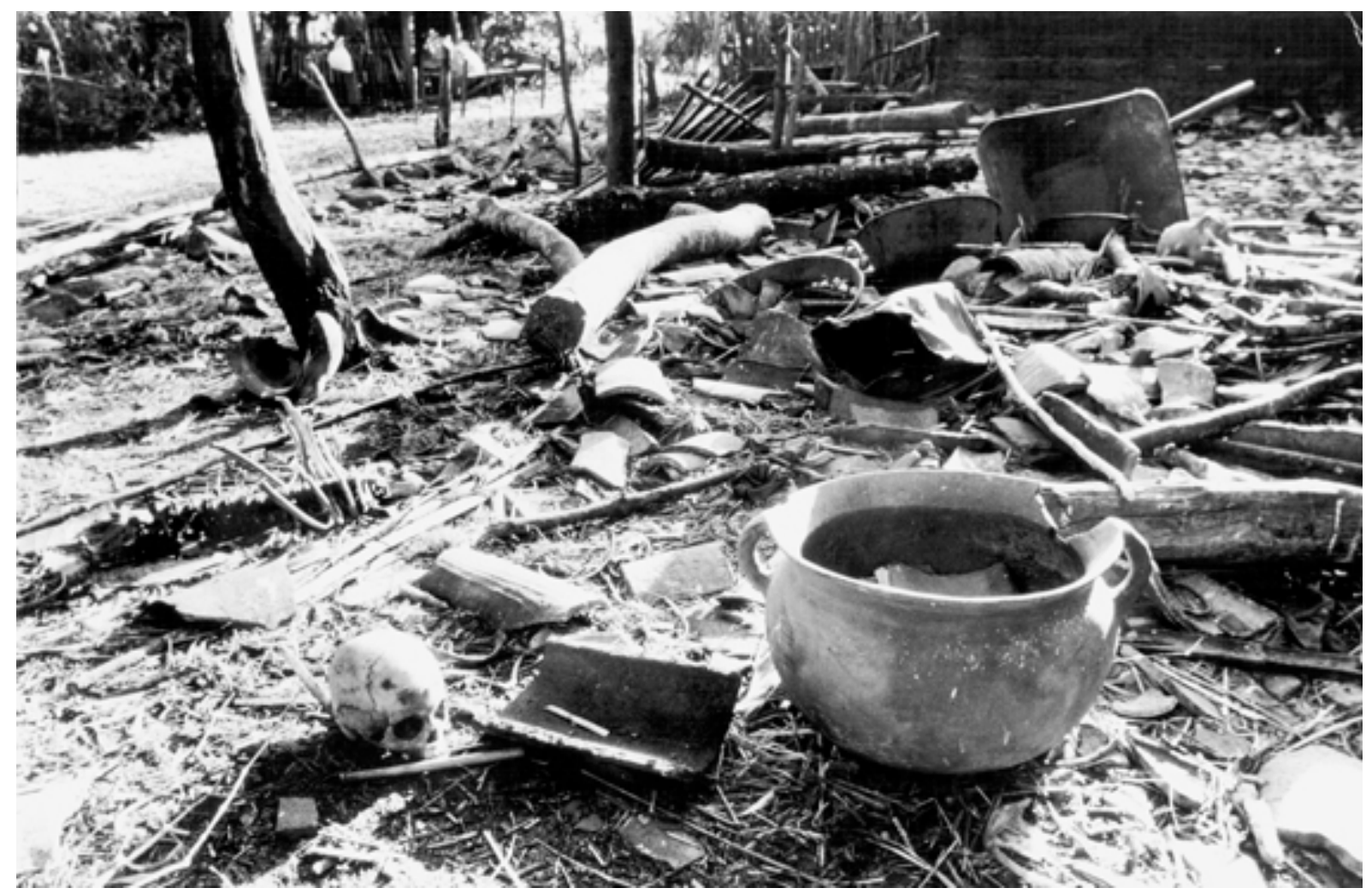

El Mozote después de la masacre, diciembre de 1981.

Archivo Museo de la Palabra y la Imagen

No presto atención a estos rasgos retóricos para encontrar lo poético en los testimonios, como sagazmente expresa Castellanos Moya en su novela Insensatez. Al transformar el pasado en un hecho lingüístico, la verdad del testigo se vuelve dramáticamente presente y manifiesta, aunque lo más profundo queda secreto e íntimo, radicalmente subjetivo. En las comparaciones y las 
enumeraciones de estos testimonios percibo el esfuerzo de comunicar la conciencia de que el exterminio se fundamentó en la reducción de sus existencias a vidas que no importan. Una deducción implícita y dolida, que afecta la identidad y a menudo suscita vergüenza. Pero el testigo necesita expresarla y volverla pública justo para replantear lo que ha sido negado: la humanidad de las víctimas.

\section{CAJAS DE CARTÓN}

Los testimonios establecen un diálogo y tratan de comunicar un sufrimiento ante el cual los seres humanos y las instituciones implicadas tendrían que responder. Así que, si la impunidad y la falta de procesos decretaron su inutilidad, la memoria traumática siguió pidiendo una narración, pretendiendo ser re-presentada. Ya que el testimonio no es solo un documento histórico y jurídico, ni solo la prueba objetiva e inatacable de un acontecimiento. El compromiso de afirmar la verdad, que tantos testigos de El Salvador asumieron a lo largo y después de la guerra, tiene que ver con la identidad profunda de la persona en su relación con los afectos y la sociedad. El testimonio, escrito u oral, es una búsqueda de la verdad y a la vez del reconocimiento que no puede rendirse al olvido por decreto. La necesidad de las víctimas de contar el pasado viene de la exigencia de reinsertarse en la humanidad de la cual fueron expulsados en cuanto vidas que no importan. A través del lenguaje, de los gestos, de las cosas que quedaron, los testigos reintegran también a los que no sobrevivieron. Narrar la historia de la masacre es reclamar la re-inserción en un espacio compartido que reconoce el valor de la existencia de los muertos y de los sobrevivientes. Por esta razón, las historias de violencia contadas por Rufina, Chiyo, Santiago y los demás, no claman venganza sino justicia, piden la escucha para el reconocimiento. Los cuerpos destrozados, desmembrados, aniquilan la singularidad del ser humano. El horror de la estrategia de la tierra arrasada implica también un delito ontológico, en la perspectiva de Arendt (1998: 353), en el que la unicidad del ser humano se cancela en una masa de seres insignificantes, en contra de los cuales todo está permitido, hasta eliminar su propia muerte.

En este escenario, en el que no hay acceso a la palabra, o esta se niega, se ignora y cae en el vacío, o la palabra no alcanza a nombrar los hechos y las emociones, si, finalmente, la palabra se rinde, quedan las ruinas. Evocar o mostrar un zapato o una camiseta es reclamar una humanidad negada. Es apelar a la vulnerabilidad compartida e interrogar por las causas y la responsabilidad de la violencia. Por eso el testimonio es sumamente dialógico y anhela ser eficaz con el lector o el oyente. No se detiene ante lo indecible del horror. Y donde enmudecen las palabras, llegan las cosas. Las palabras del testigo convocan lo ausente, las cosas lo hacen íntimamente efectivo. En una entrevista, José Cornelio Chicas, que perdió a toda su familia en la masacre de El Junquillo (1981), muestra los dos sombreros que le regaló a su hijo de seis años, uno para jugar, el otro para trabajar. Comenta don Cornelio: "la sorpresa fue que cuando me hicieron llegar acá los restos...que alegría ver los sombreritos del niño... cuando veo los sombreritos pienso que posiblemente espiritualmente está conmigo. $\mathrm{Y}$ al morir yo, estos sombreritos se van a ir conmigo". 


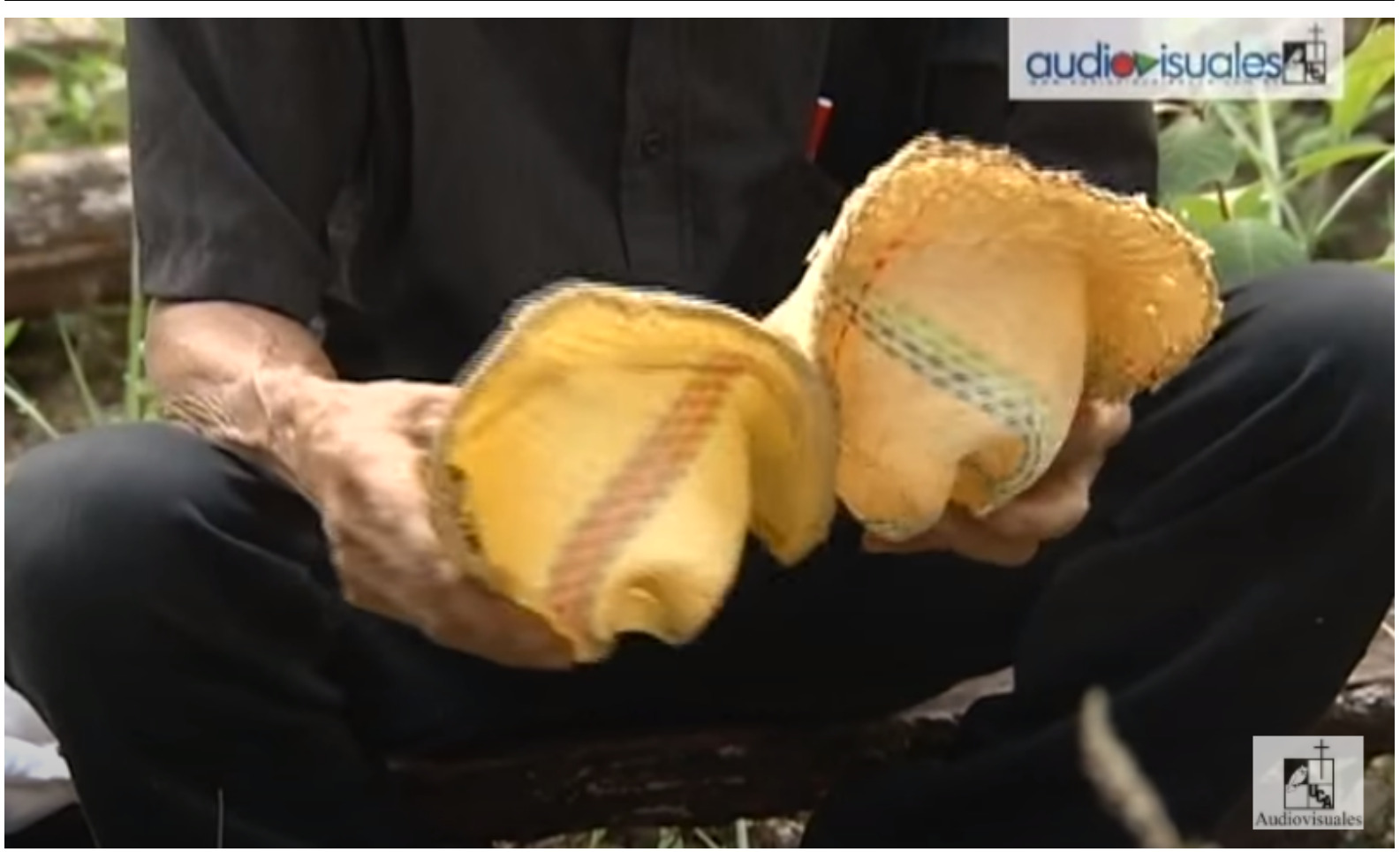

José Cornelio Chicas muestra los sombreritos de su hijo asesinado.

Imagen del video Voces en el muro (2014) de Audiovisuales UCA
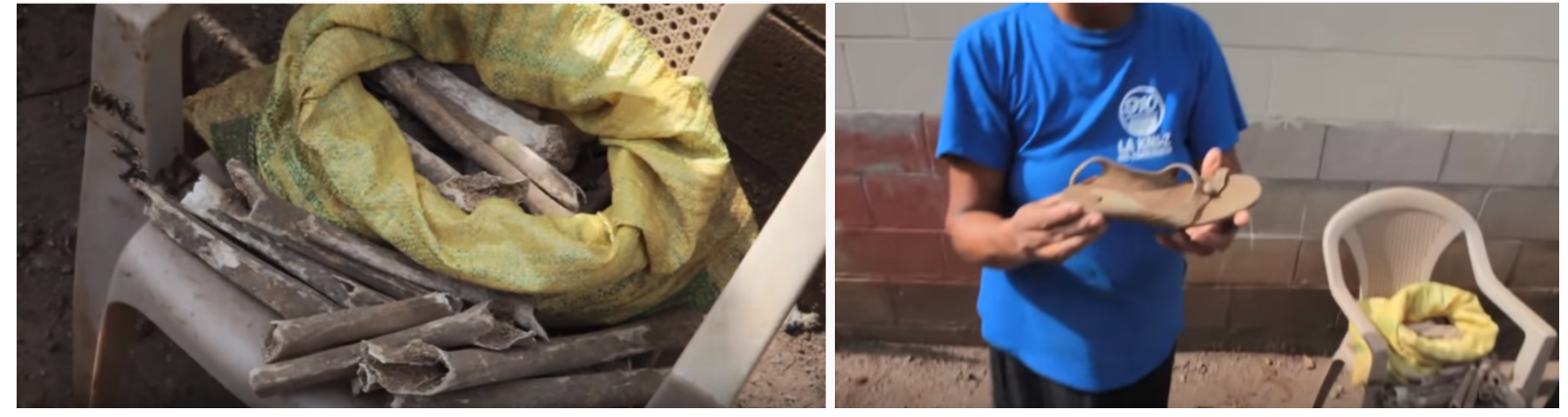

Huesos y un zapato exhumados en Arcatao

Imagen del video Exhumaciones en Arcatao. Justicia pendiente (2010)

de Audiovisuales UCA

San Francisco Echeverría (Cabañas): el primer resto material es un edificio lleno de huecos de ametralladora. En un cuarto pequeño se guardan los despojos de las víctimas de la masacre, entre las flores. En otros pueblos se encuentran más paredes ametralladas. No son monumentos, sino que, siguiendo a Halbwachs, son la imagen espacial de la historia y su memoria.

En muchos otros pueblos pequeños de Morazán, San Vicente, Chalatenango, en capillas o también en espacios privados, en el rincón de un cuarto, se conservan huesos, pedacitos de ropa, zapatos desparejados, juguetes, utensilios. Las prendas de vestir quemadas, guardadas en tecas de vidrio o en cajas de madera, no son reliquias (objetos que descansan en paz), no son restos gloriosos de una historia acabada y quizás épica. Son restos que operan en un espacio compartido, material o simbólico, y adquieren un papel histórico, jurídico y afectivo. A veces las cajas son de cartón. A mi pregunta sobre por qué usar un material tan frágil para algo tan importante, don X contestó: "así toditos tenemos que cuidarlas...que estar pendientes". 


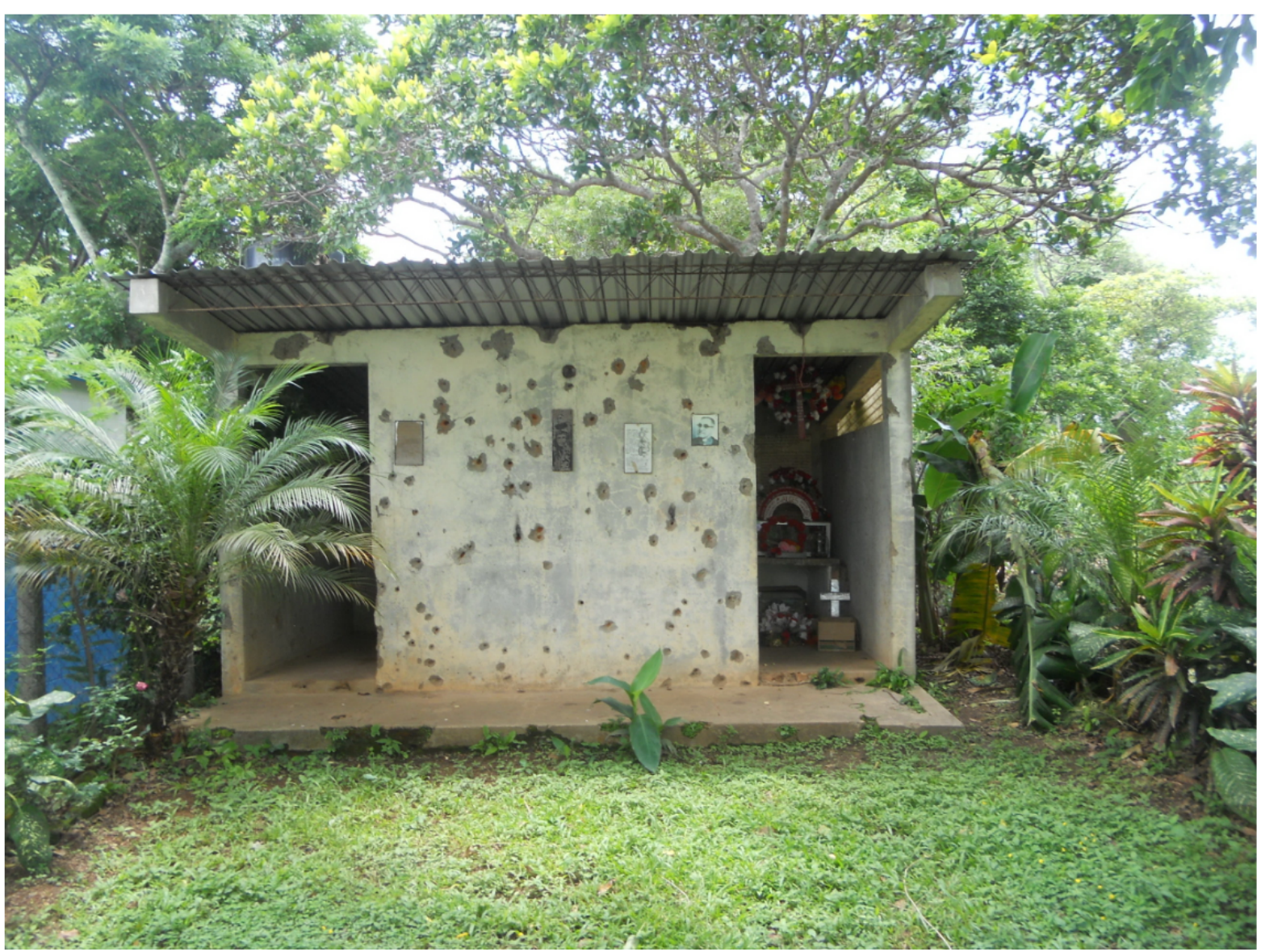

San Francisco Echeverría, 2015.

Foto de la autora

Con las cosas y los lugares, sean las paredes o los despojos, se establecen una relación y una percepción que no son solamente visuales. Como cuando se acaricia la foto de un difunto, los afectos pasan también por el tacto. Al contar su experiencia de violencia, los testigos muestran los sitios, los indican y tocan las paredes, escarban el polvo dentro de un hueco de ametralladora, o sus dedos dan vueltas a un pedacito de camiseta. Una memoria que recurre al tacto para aprehender y comunicar el pasado. Lo material, y los sentidos que implica, confieren densidad a la narración verbal, la sustancian y desplazan la memoria hacia un diferente orden comunicativo. Estos restos materiales expuestos a la mirada y al tacto, descubren la vida ofendida y humillada, pueden suscitar compasión, pero también se vuelven actividad: los restos se desplazan de lo privado a lo público. 


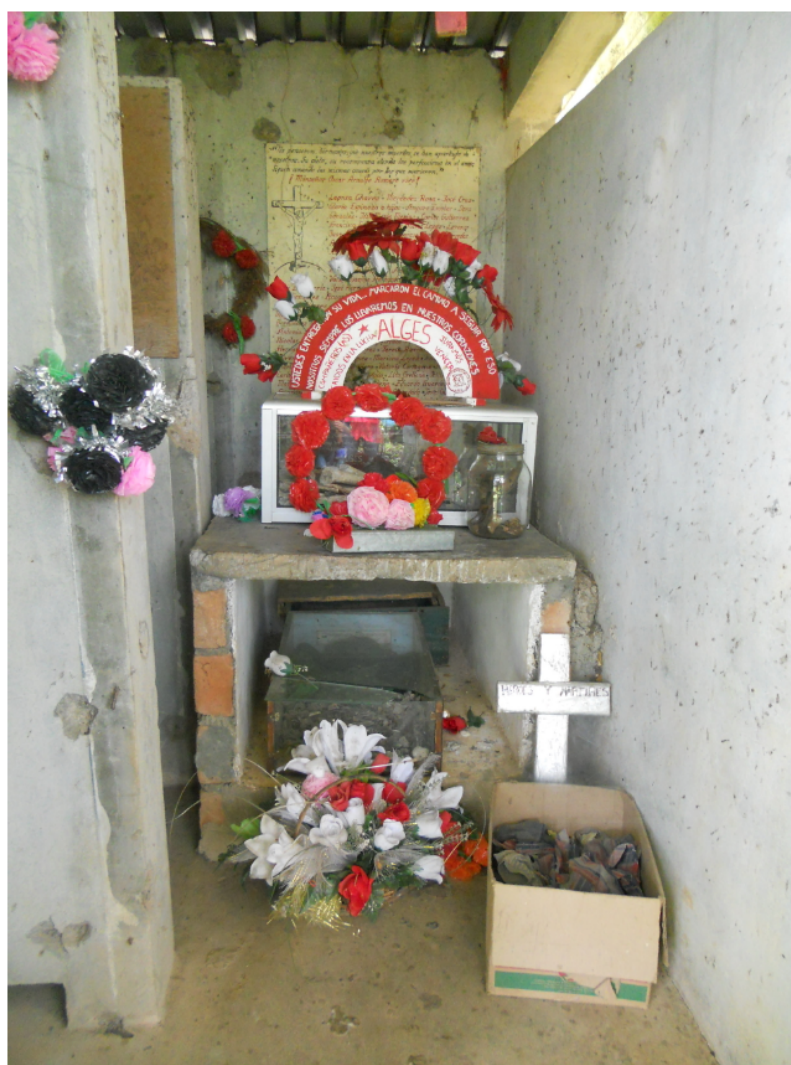

Una caja de cartón guarda los restos de las víctimas de San Francisco Echeverría. Foto de la autora

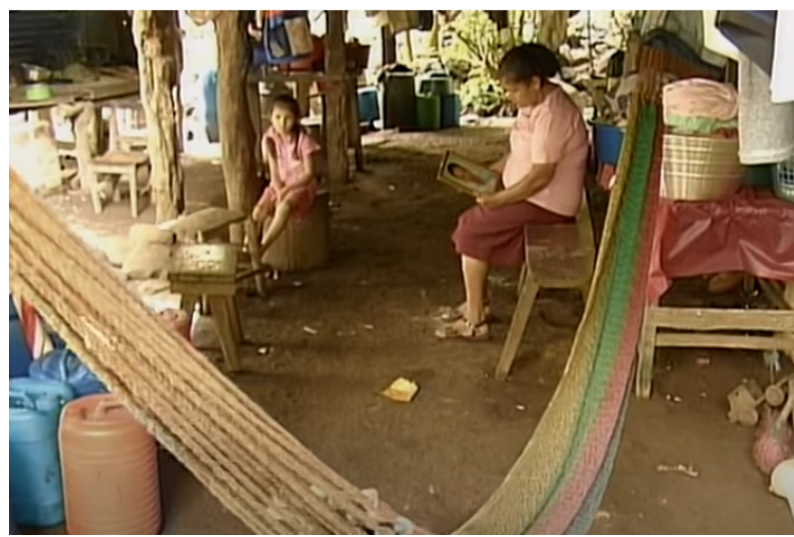

Isabel Granadeno mirando la foto de su familiar asesinado Imagen del video Masacre de Santa Lucía (1980-): Memoria de las víctimas

\section{EL IMAGINARIO TESTIMONIAL Y LAS COSAS}

Con el contexto de olvido e impunidad, que puede originar indignación, angustia, aflicción o más bien resignación o cinismo, se enfrentan también la narrativa, la poesía, el teatro, el arte y la fotografía de El Salvador. De hecho, en todos los países latinoamericanos todavía marcados por heridas abiertas, hubo y sigue habiendo la necesidad de contar otra versión de la historia, no solamente a través del testimonio. La ficcionalización de eventos históricos traumáticos puede 
mover de la conciencia de los límites del testimonio y a menudo lidia con la cuestión de comunicar el horror sufrido por otros y hablar en su lugar. Frecuentemente, las ficciones que recuperan el imaginario testimonial de las masacres en El Salvador reclaman la contundencia de lo material. Los objetos son investidos ontológicamente: pueden presentificar la ausencia, reclamar justicia, o más bien pedir desapego y alejamiento. Por lo tanto, los restos materiales, representados en la escritura, mantienen con el texto la triple relación antes individuada: significancia, casualidad, petición.

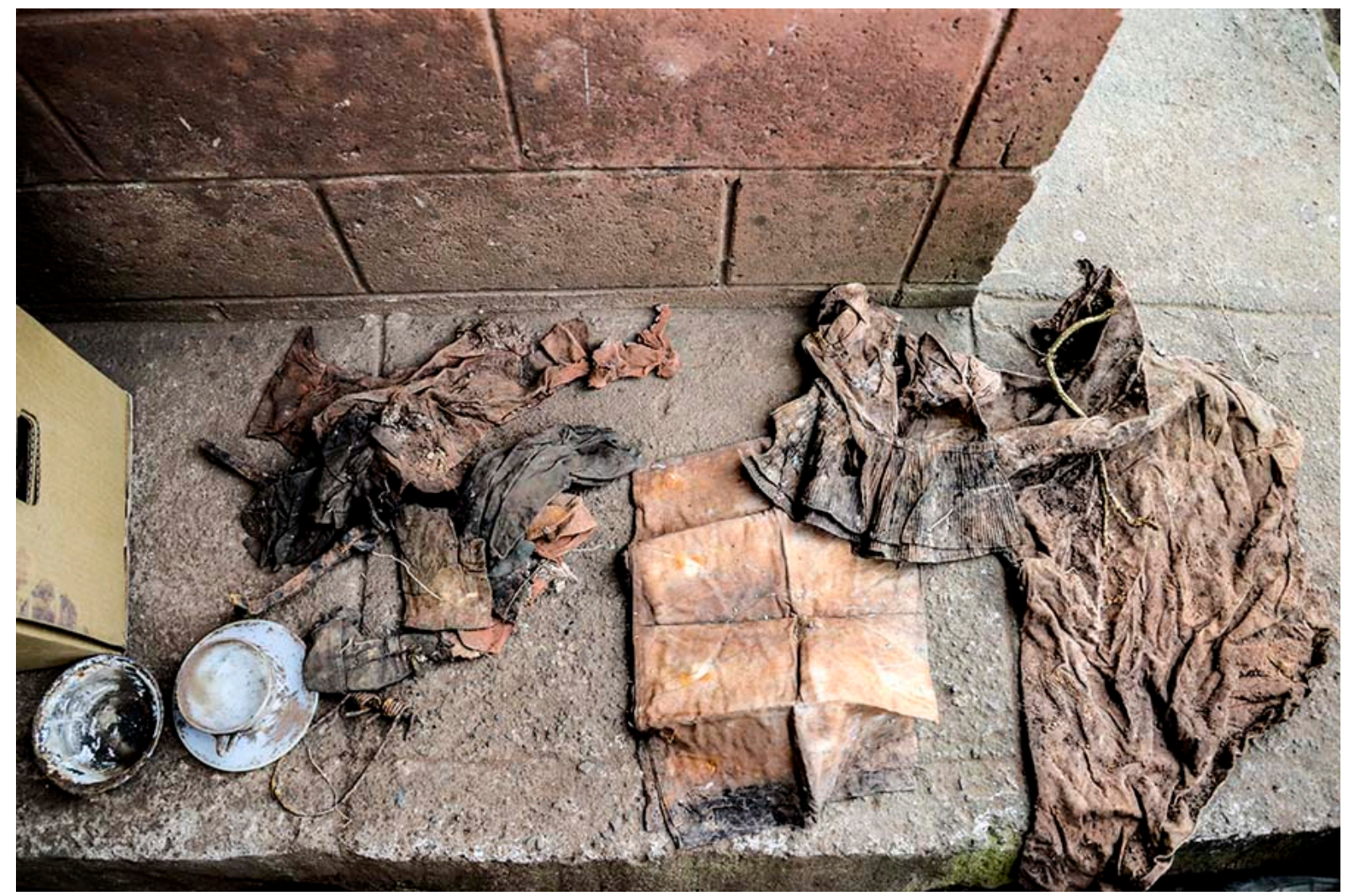

Las cosas testimonian a través de su mudez.

Foto de Fred Ramos, La vida interrumpida en El Mozote

Me voy a referir a dos autoras salvadoreñas nacidas en los 70 , que asumieron la tarea de trabajar con y por la memoria. Ya he trabajado difusamente la obra de ambas, pero aquí quiero retomar solamente dos textos analizándolos desde la perspectiva de los restos materiales y del imaginario testimonial. El primer texto es el cuento "Manual del hijo muerto" de Claudia Hernández, publicado en 2007. El cuento consiste en la fingida transcripción de la página 23 de un pretendido manual cuya finalidad es otorgar a los padres unas instrucciones para recomponer al cuerpo despedazado de su hijo. El tono frío y paternalista, hasta irónico, de las explicaciones produce un contraste estridente tanto con el dramatismo de la situación textual (el hallazgo del cadáver destrozado de un familiar) como con las situaciones extra-textuales, a las cuales implícitamente el cuento se refiere. El proceso de reconocimiento, cuya importancia se ha repetidamente señalado en este trabajo, en el cuento se reduce a una tarea expeditiva: "con frecuencia el reconocimiento puede realizarse a simple vista, pero no está de más comparar la dentadura del cadáver con las placas registradas en el archivo del dentista de la familia" (107). Se trata de un problema sustancialmente práctico: "asegúrese de no firmar de recibido antes de estar 
completamente seguro(a) de que el contenido del paquete le pertenece en su totalidad. Recuerde que no se aceptan devoluciones" (107). El texto facilita unas indicaciones sarcásticas: "se recomienda tener a mano una caja de pañuelos desechables y no fumar durante el proceso, a fin de evitar humedecer o dañar con fuego y cenizas las delicadas piezas" (107). La irreverencia y el cinismo del "Manual del hijo muerto" construyen un contrapunteo audaz y casi insolente con las narraciones testimoniales atormentadas sobre cuerpos destrozados. Refieren Gloria, Teodora y Arely, en las entrevistas publicadas en "Trasmallo":

Los chucos siempre traían orejas, brazos, piernas de los compas que se habían muerto. Los soldados hicieron groserías. Los soldados los descabezaban, les quitaban orejas y otras partes para que sufrieran más y para darles miedo a la otra gente (Gloria) (Kenealy 2009: 22)

Cuando hubo la masacre del Sumpul, yo andaba pescando con una atarraya. Un brazo entero me cayó en la atarraya. Era de una muchacha. (Teodora) (Kenealy 2009: 21)

Siendo muy chica vi a unas muchachas cortadas de su carita con su cabello colgando, y sin cabezas, o cortados los pechos, o metidas agujas, desnudas, violadas. (Arely) (Kenealy 2009: 27)

Irónicamente, el "manual" también provee un Apéndice B con el esquema básico del cuerpo humano "para aquellos a quienes las variadas manifestaciones de la emoción les impidan reconstruir mentalmente la figura del hijo" (108).

La intención de Claudia Hernández no es disminuir el horror, menos aún ridiculizar las vivencias dramáticas que los testigos recuerdan y cuentan. Como muestra Adriana Cavarero, la violencia que desmiembra es un horror paradigmático porque "ofende a la dignidad ontológica que la figura humana posee y lo hace inmirable” (2009: 25). El cuento suscita incomodidad y justamente por este motivo actualiza y materializa el dolor sufrido por tantos salvadoreños por el hallazgo de un cuerpo despedazado. Funciona, así, como antídoto a la banalización del mal y a la práctica del borrón y cuenta nueva.

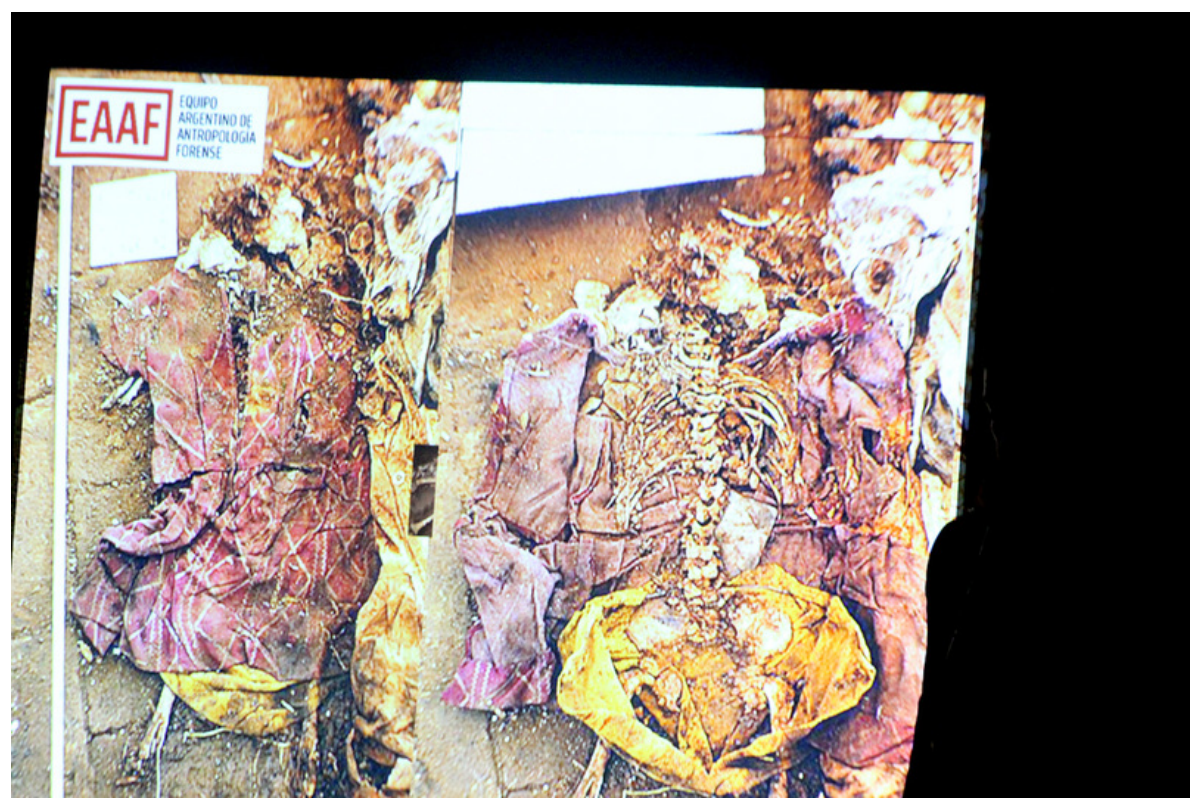

https://www.transparenciaactiva.gob.sv/ckeditor_assets/pictures/623/content_IMG_7162.jpg 
En la escena del cuento resaltan dos objetos: el cadáver y sus vestidos. De hecho, el cuerpo aquí es una "cosa" en forma de trozos que se tiene que armar. El texto advierte que no se aceptan devoluciones, como si fuera un producto. Incluye las instrucciones de montaje, como si se tratara de un mueble de Ikea y aconseja proceder en la mesa del comedor y luego llevar el cuerpo a su cama, en donde lucirá espléndidamente. Con paternalismo, el manual advierte a los padres de que deben acertar la combinación de la vestimenta para no tener que cambiarla:

TIP: extender el cuerpo sobre la cama en posición decúbito dorsal, con una pierna flexionada y sin arrugas en la ropa produce siempre la sensación de tener nuevamente en casa no solo a un hijo perfecto, sino a uno vivo. (108)

El texto remite con sarcasmo a las antes mencionadas devoluciones de los despojos a los parientes de las víctimas. Y el humor negro, que atraviesa el texto, surte otros efectos respeto de lo real maravilloso, a través del cual García Márquez cuenta con levedad la llegada de Rebeca con su "talego de lona que hacía un permanente ruido de cloc cloc cloc, donde llevaba los huesos de sus padres" (2005: 132). En Cien años de soledad, los huesos, en espera de que haya un lugar digno para sepultarlos, circulan por la casa, estorban por todas partes "con su cloqueante cacareo de gallina clueca" (134). Pero no son ridículos. En cambio, en el cuento de Claudia Hernández la trivialidad de la enunciación rebaja las circunstancias. Sin embargo, no es un cuento de mal gusto. A través de la incorreccion y del distanciamiento feroz de las víctimas (los cuerpos son puros objetos, los familiares simples ensambladores de pedazos) la escritora muestra la violencia del discurso cínico y la brutalidad implicita en la aceptación de un estado de cosas al cual no se puede dar asentimiento. Es un cuento políticamente incorrecto que recurre a lo patético y lo grotesco. Pero patéticos y grotescos no son el cadáver y los padres, sino el manual y su voz enunciadora. Entonces, si como he señalado, el cuento incomoda al lector por las imágenes macabras y por el contraste demasiado estridente con los testimonios, también agobia por su función y la manera de cumplir con su obligación. La instancia emisora del supuesto manual se siente satifecha consigo misma y realiza un discurso paradójico y autoritario, puesto que se fundamenta en la sumisión incondicional de los destinatarios a una órbita presuposicional e incontestable: la impunidad.

El texto porpone el arreglo de un cuerpo destrozado que metafóricamente remite a la pretensión de ajustar una historia fragmentada, suturando de manera artificiosa e insensata los cortes de la violencia sufrida. Pero las partes quebradas del cuerpo del hijo o del cuerpo del país no son recomponibles bajo el signo de la autoridad. Excepto cuando el cuerpo (individual y social) sea tratado como un mero objeto. Claudia Hernández no refiere la fecha de publicación del fingido "Manual del hijo muerto", por lo tanto, los cadáveres despedazados (muchos, si se publicó un manual para su tratamiento) pueden venir de la violencia del conflicto armado o de la más reciente violencia de las maras. La falta de una referencia temporal precisa puede leerse como una puesta en escena de la perduración de crímenes sin responsables y de una condición permanente de precariedad y vulnerabilidad en El Salvador. De todas formas, el hallazgo de cuerpos destrozados es un acontecimiento siempre actual en El Salvador: en noviembre de 2016, el Equipo de Antropología Forense del Instituto de Medicina Legal exhumó en El Mozote los restos de la familia Márquez Pereira, compuesta por 9 personas, todas asesinadas durante el operativo "Operación Rescate": de los esposos José María (62 años) y Donatila (55); de sus hijos 
Sofía (32), José Evenor (19), Fredy (13) y Óscar (22); de los nietos Edenilson (7) y Balmore (8) y una niña de un año y medio cuyo nombre se perdió. Del suelo, juntos con los huesos, salieron unos objetos. Como escribe el fotógrafo salvadoreño Fred Ramos que fotografío los objetos (2017), estas cosas hablan de una cotidianeidad interrumpida: una taza, un pichel de peltre para leche, tijeras, unas chibolas, restos de la piedra de moler, dos linternas... Para el artículo dedicado a la exhumación, publicado en "El faro", Fred Ramos opta por unas fotografías en primer plano sobre fondo negro.

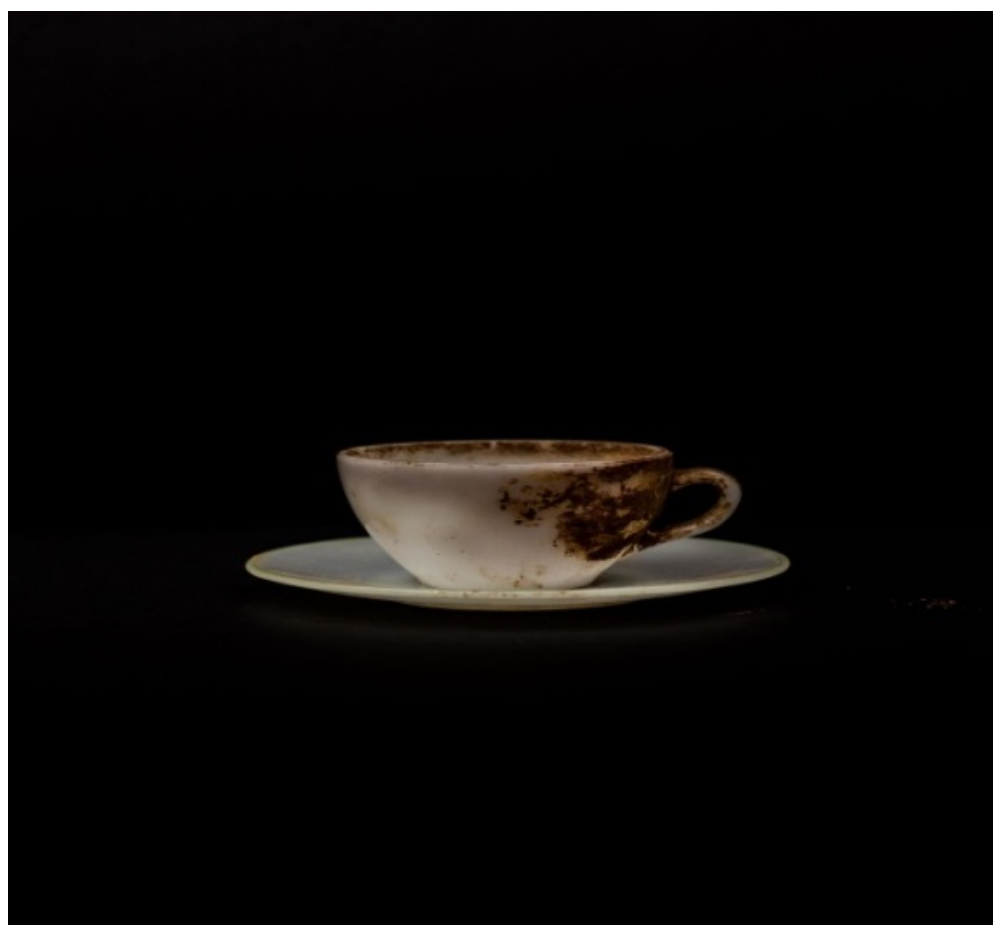

Foto de Fred Ramos, La vida interrumpida en El Mozote

El vestido sin cuerpo, las chibolas sin niños, implican inferencias interpretativas. De nuevo, estas cosas son signo, efecto y petición.

A veces el proceso es invertido. A lo restos materiales desenterrados se suman las cosas enterradas. Por ejemplo, en El misterio de las utopías de la dramaturga salvadoreña Jorgelina Cerritos, un personaje decide sepultar las cosas de su hermano desaparecido. En la obra teatral se profundiza el rol y el significado de la prueba a través del contraste entre dos clases de objetos: por un lado, un archivo deteriorado y por el otro unas chibolas y una camiseta blanca. El primer objeto, un montón de pliegues amarillentos, permanece en el centro de las tablas durante toda la representación. Las chibolas y la camiseta, en cambio, son solamente aludidas. Asimismo, el tiempo presente es representado en la escena, mientras el pasado es evocado a través de las palabras de los actores. El pasado coincide con el conflicto armado y la infancia de tres hermanos. Los niños fueron víctimas de un bombardeo y uno de ellos desapareció. La hermana recogió la camiseta blanca que se había quitado y unas chibolas que rodaron en la tierra. En el tiempo presente, los niños sobrevivientes ya son adultos que deben negociar con el pasado. La hermana, tras haber dedicado mucho tiempo a la búsqueda del hermano muerto o desaparecido, decidió enterrar sus restos: la camiseta y las chibolas. Otro hermano, que se fue de El Salvador, 
que nunca contribuyó a la investigación, ahora quiere buscar al desaparecido porque puede tener acceso a un archivo del Departamento de Inteligencia de la Fuerza Armada Salvadoreña, recopilado en los años 80, que contiene miles de nombres y fotos de sospechosos. El hallazgo del archivo, llamado "El libro amarillo", es una circunstancia real, acontecida en 2013. El hermano piensa escudriñar todas las fotos para encontrar un parecido con el rostro infantil que recuerda. $\mathrm{El}$ archivo es una oportunidad para encontrar un indicio de las responsabilidades de los militares. Pero la hermana ya tiene una idea diferente de lo que es una prueba:

LA HERMANA: Aún tengo la camiseta que se había quitado.

EL HERMANO: Aquí está su nombre, su foto. La prueba.

LA HERMANA: ...y un par de chibolas, de las que salieron volando... (44)

La hermana revindica el derecho al olvido y quiere interrumpir el movimiento de ida y vuelta implicado en los restos materiales en cuanto huellas: de lo alucinante a lo nimio, de lo nimio a lo alucinante?

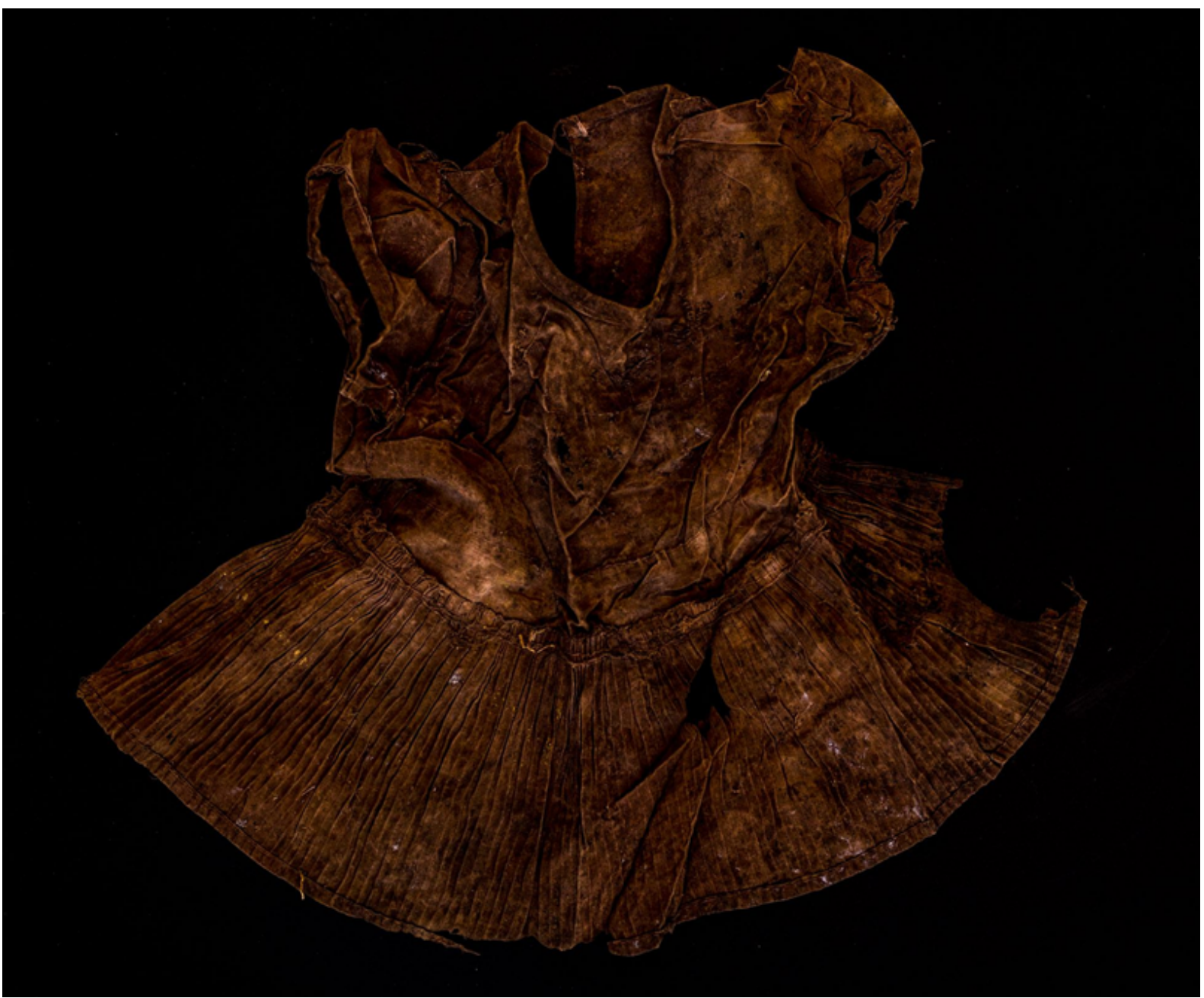

El vestido de la niña menor de Oscar Márquez, de un año y medio, sin nombre

Foto de Fred Ramos, La vida interrumpida en El Mozote

\footnotetext{
${ }^{7}$ Para el desarrollo de la trama y su análisis ver Jossa (2019).
} 


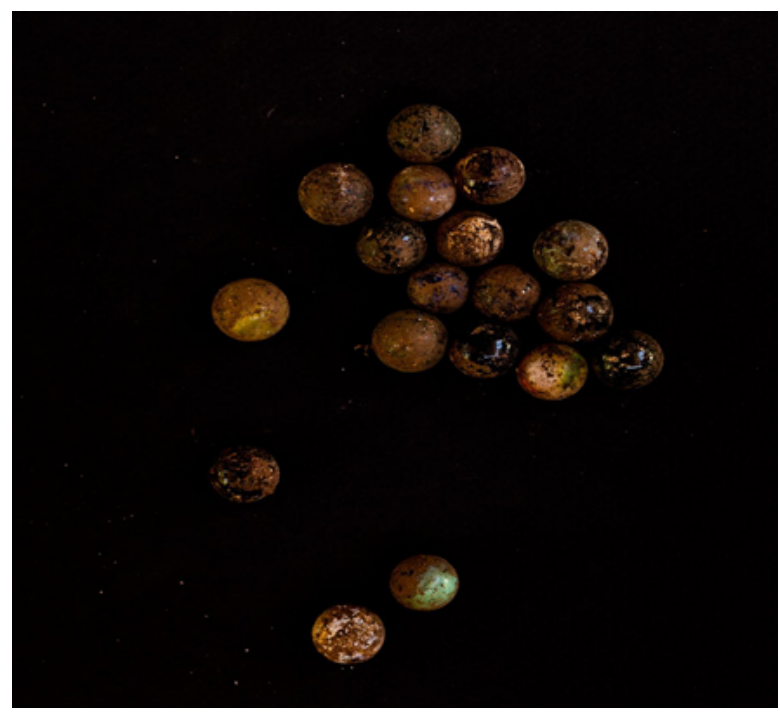

Chibolas

La vida interrumpida en El Mozote, foto de Fred Ramos

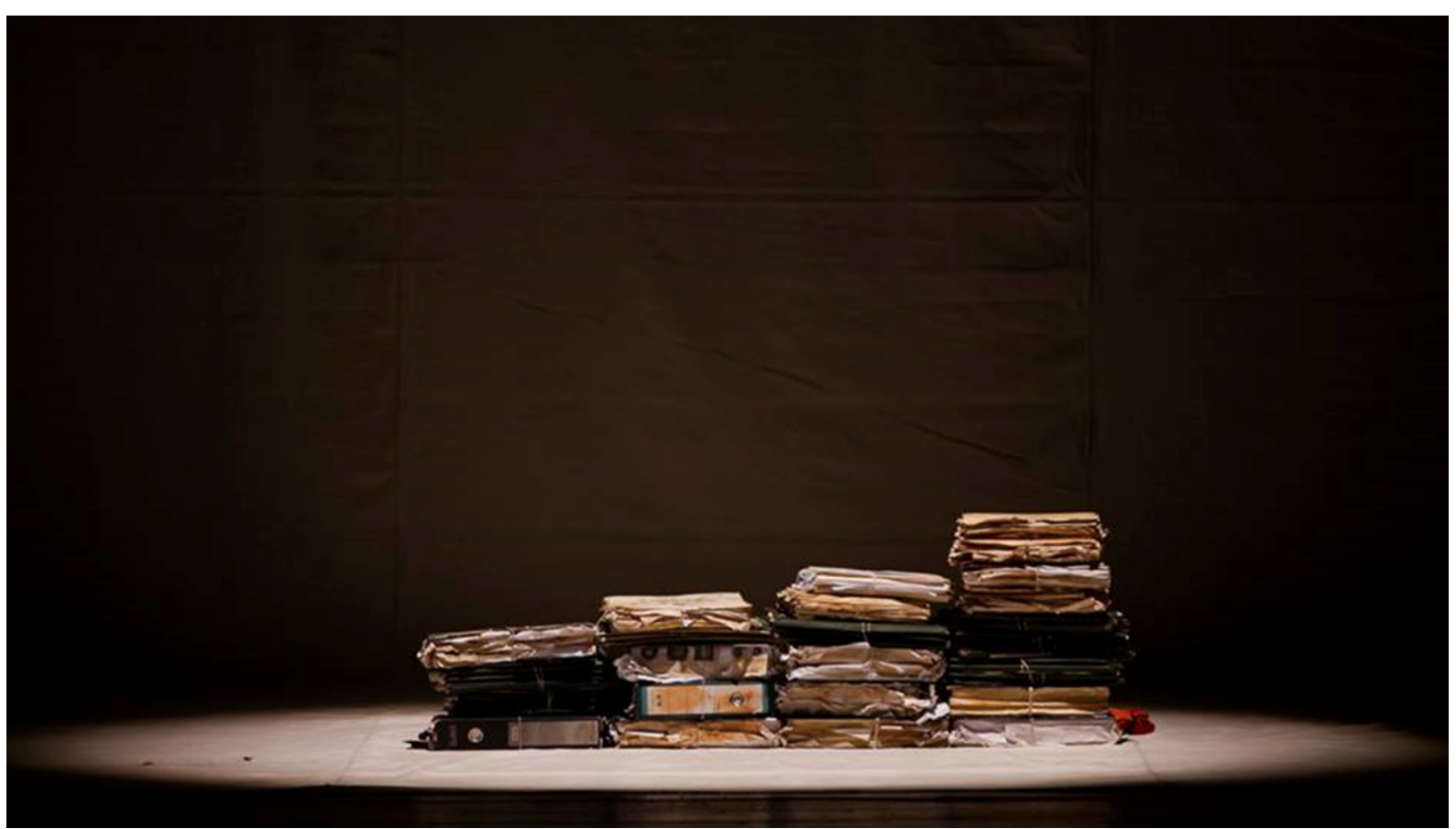

13703. El misterio de las utopias. Foto de René Figueroa

\section{DE LOS ESCOMBROS A LOS RETOÑOS}

La historia de El Salvador del siglo xx fue marcada por un estado de excepción permanente que permitió la supresión del derecho para la mayoría de la población. Como hemos visto, las masacres fueron parte de una estrategia militar deliberada, la tierra arrasada, que significó acabar con todo, todos los cuerpos humanos y animales, todas las cosas. En los crímenes de masa o selectivos, los cuerpos mismos se volvieron puro objeto de violencia. La naturaleza también fue reducida a objeto de destrucción. El fundamento de la injusticia consiste en esta conversión en 
objeto de dominio de las diferentes formas de vida, una conversión que supuestamente "autorizaría" el exterminio. Terminada la guerra, se pretendió el olvido del pasado sin posibilitar una reconciliación verdadera. Oficialmente prohibida, la memoria empezó su trabajo. "Recuerdo" es un substantivo que remite a la materialidad de la memoria y a la vez es la primera persona del verbo "recordar", o sea, como asevera Portelli, es "una actividad, una labor" (Álvarez Bravo8, 2017: 544). Recordar es establecer una ligazón dinámica entre pasado y presente. Contra la amnesia, es necesaria una memoria que sea un proceso, que permita el surgimiento de la esperanza y la justicia. Los objetos presentados: densos y carentes, reales en los testimonios o imaginados en la ficción, presentes o evocados por las palabras de los testigos, configuran este recordar. Todos son objetos comunes y el adjetivo "común" se refiere tanto a su uso cotidiano como a su dimensión compartida. Las cosas comunes presentadas en este último párrafo siguen siendo signo, efecto y petición y construyen una memoria en movimiento, como dice Santiago al explicar la misión del MUPI, que permite conocer las injusticias sufridas y promueve la responsabilidad por el futuro. Recordar a través de las cosas es un proceso que puede interrumpir la reproducción de la exclusión y del silenciamiento de los subalternizados. Es el paso de los escombros a los retoños, del cual ofrezco algunos ejemplos.

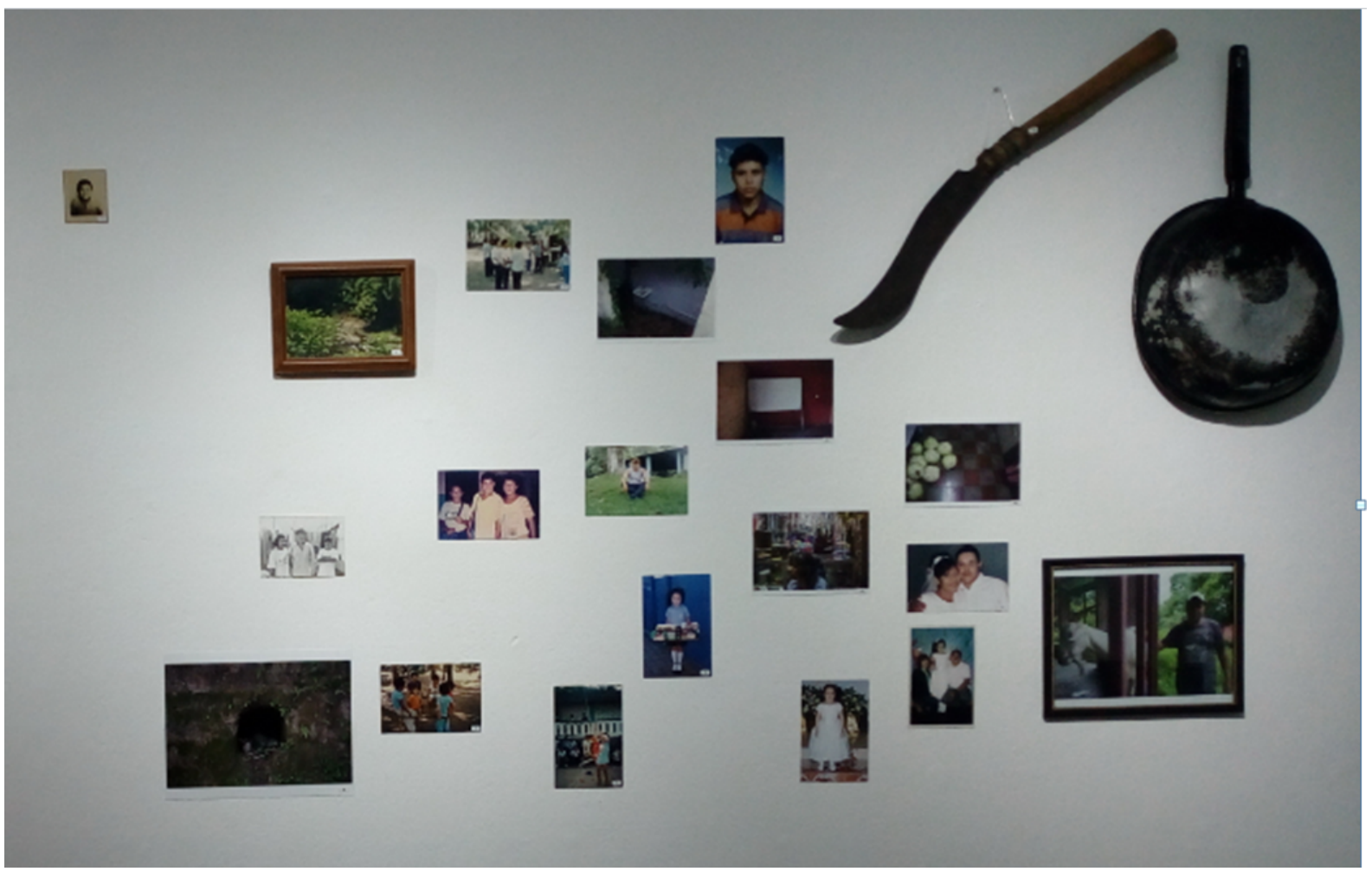

“Re: Construcción”. Foto de la autora

"Re: Construcción”. En junio de 2017 en el Centro cultural de España en San Salvador (CCESV), se realiza una de las etapas de la exposición itinerante "Re: Construcción" sobre el legado de la guerra. El proyecto consiste en tres secciones. El núcleo central de la primera y de la segunda parte son las cosas. En una sección de la sala, unas mesas reúnen algunos objetos y fotos

8 Álvarez Bravo, Paulo. "La historia oral es un arte de la escucha. Entrevista a Alessandro Portelli". Kamchatka. Revista de análisis cultural 9 (2017): 543-552. 
de personas relacionados con la guerra, conectados a entrevistas y sonidos de fondo. A un mural interactivo, la segunda parte de la muestra, el público puede agregar sus propios objetos (fotos, cosas, escritos...) en relación con la memoria de la guerra. La articulación de las dos secciones establece un enlace entre presente y pasado y crea, a través de la materialidad de las cosas, una memoria activa y una conexión entre las generaciones, una ligazón dinámica.

En el ámbito de la tercera parte del proyecto, la artista Verónica Vides presentó La Barrida (2010), un performance con 20 excombatientes y lisiados de guerra quienes, entre las ruinas de la iglesia de Aguacayo, barren el piso de un polvo que no puede desaparecer. Su tarea interminable y agotadora se refiere a la supuesta limpieza (destrucción) realizada durante el conflicto armado en El Salvador: hombres y mujeres, con sus escobas, no consiguen limpiar el sitio, sino levantan más polvo, ensuciándose.

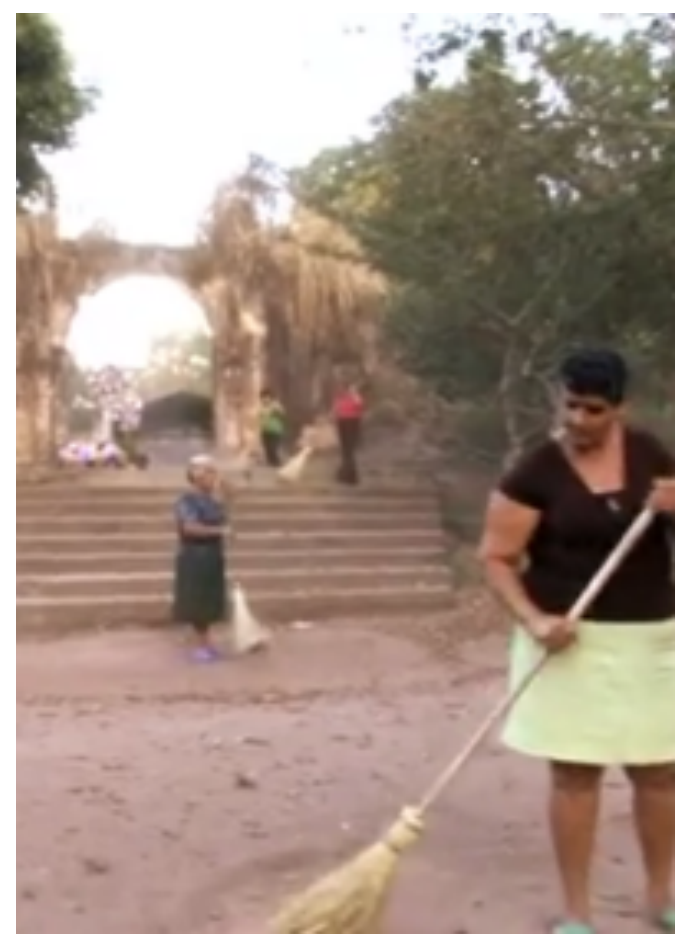

La Barrida de Verónica Vides

El concepto de limpieza falaz y la invitación a recordar son trabajados también por Carmen Elena Trigueros en Lavandera (2014). La artista presenta el objeto por excelencia símbolo de la patria, una bandera nacional de grandes proporciones. La bandera está en el suelo y una mujer la enjabona, la friega, la enjuaga, como una sábana enorme. Luego la deja en las escaleras del monumento a Cristo el Salvador. La estatua se encuentra en la Plaza Salvador del Mundo que en 2010 fue remodelada y las obras incluyeron la renovación del área de las banderas. Para Carmen Elena Trigueros, esta transformación del espacio, realizada por el ayuntamiento, es una muestra de una "nueva higiene como un símbolo de su control sobre una ciudad por lo demás caótica" (2014). Entonces, la acción es un acto político emancipatorio que trata de resignificar los espacios públicos e invita a otras formas de convivencia. Al mismo tiempo, pone en escena la necesidad de limpiar un país que quedó sucio después del conflicto armado. Si la guerra civil, y 
ahora la violencia diaria, manchan la bandera, una nueva conciencia ciudadana, que enjabona, friega, lava, puede ayudar a limpiar la historia y proyectar un futuro más justo.

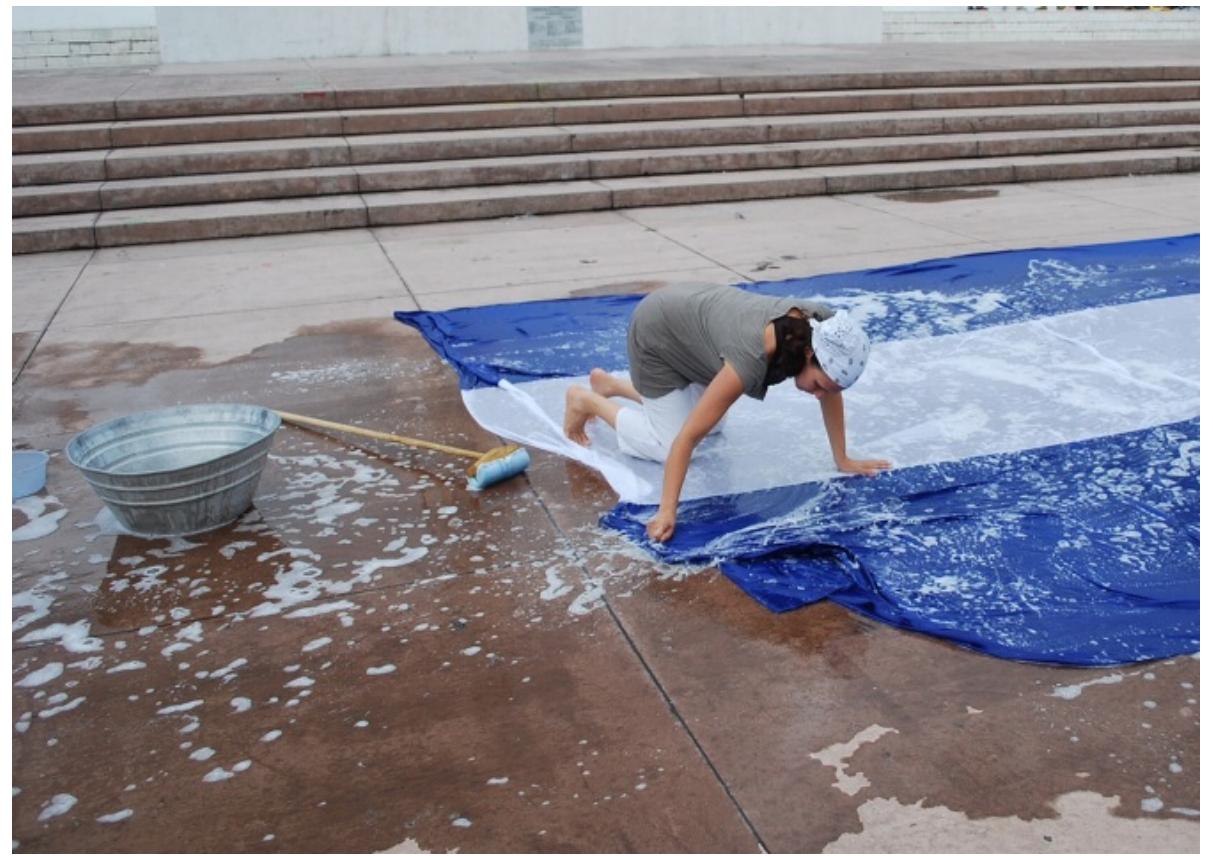

Lavandera (2014) de Carmen Elena Trigueros

"Un manzano rosa". Los muros ametrallados de San Francisco Echeverría definen un espacio de la memoria doliente. Este espacio se puede complementar con otra dimensión espacial, la del paisaje. En El Salvador, la naturaleza de muchos sitios es históricamente significante y emotivamente anclada. Al final de la entrevista con el periodista Jorge Ramos, Rufina Amaya, tras haberle mostrado un manzano rosa, el árbol detrás del cual se escondió, le ofrece al entrevistador una ramita de la planta. Luego lo invita a probar el fruto diciendo "Es muy dulce, es el árbol de la vida".

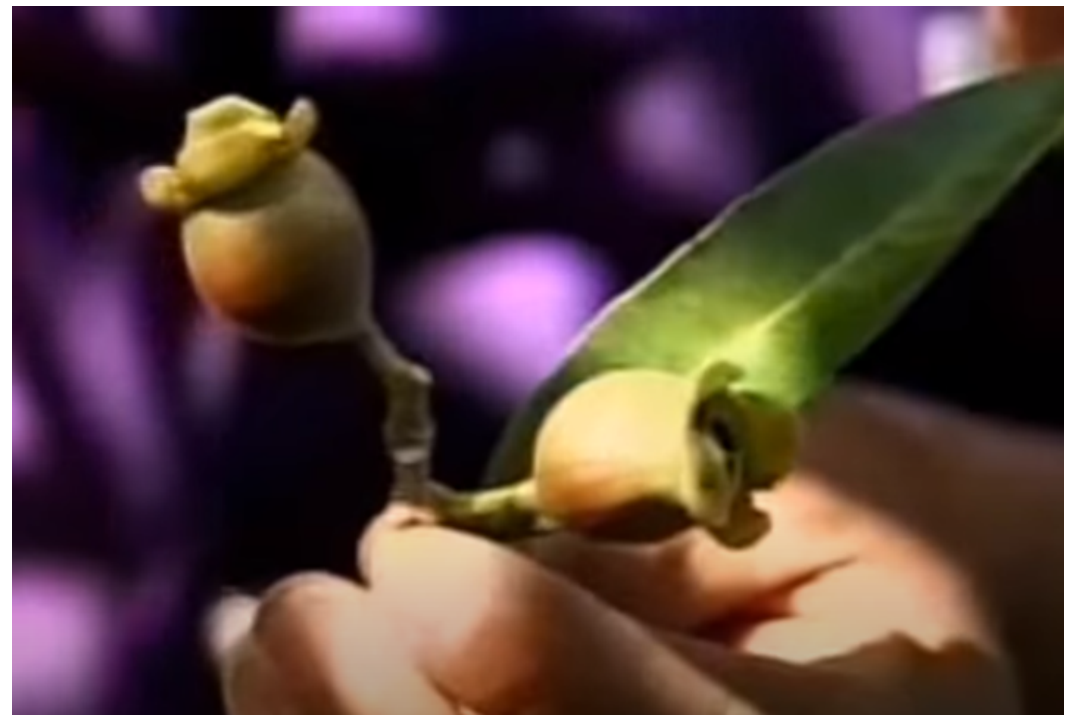

Imagen del video Jorge Ramos entrevista a Rufina Amaya 
“Luciérnagas". Tres años después de la masacre de El Mozote, en 1984, Santiago y sus compañeros, durante la noche, dejaron el Pericón porque el ejército había detectado la posición de Radio Venceremos. Esta vez se les presentó un espectáculo diferente. Ya no es una escena "alucinante", más bien "deslumbrante". Los caseríos seguían destruidos, las ruinas deshabitadas, pero sobre los escombros se manifestó una forma de vida:

Se encendieron miles de luces diminutas. Sorprendido, durante algunos segundos reconocí las ruinas de la iglesia de El Mozote. Alborotadas luciérnagas nos tendían una inusitada emboscada de claridad. Se desvanecían y luego reaparecían en una luminosa danza intermitente.

-Son las ánimas de El Mozote!

Fue la voz inconfundible de padre Rogelio Poncel.

Aquellas luciérnagas en El Mozote me reafirmaron el compromiso de dejar memoria escrita sobre la masacre, que, en aquel momento, poderosas fuerzas trataban de borrarla de la historia. (127)

En su "afán de tejer la memoria" (Henríquez Consalvi, 2017: 9), ahora el MUPI también acompaña a las comunidades que después del conflicto armado repoblaron nuevos territorios.

"Libros quemados". Como ya he señalado, la destruccion de los archivos de los militares fue un arma importante para la negación y el olvido, así como su hallazgo representa una posibilidad de esclarecimiento histórico, como el descubrimiento del Libro amarillo al cual se refiere Jorgelina Cerritos. Ka'i' K'atun es una obra de la artista salvadoreña Beatriz Cortez y del Colectivo Kaqjay Moloj. El título se refiere al concepto cíclico del tiempo de la cosmovisión Maya. Como explican los autores, la instalación "oscila entre un pasado de censura y de violencia, un presente de empoderamiento y acceso al conocimiento, y un futuro definido por los deseos de la comunidad".

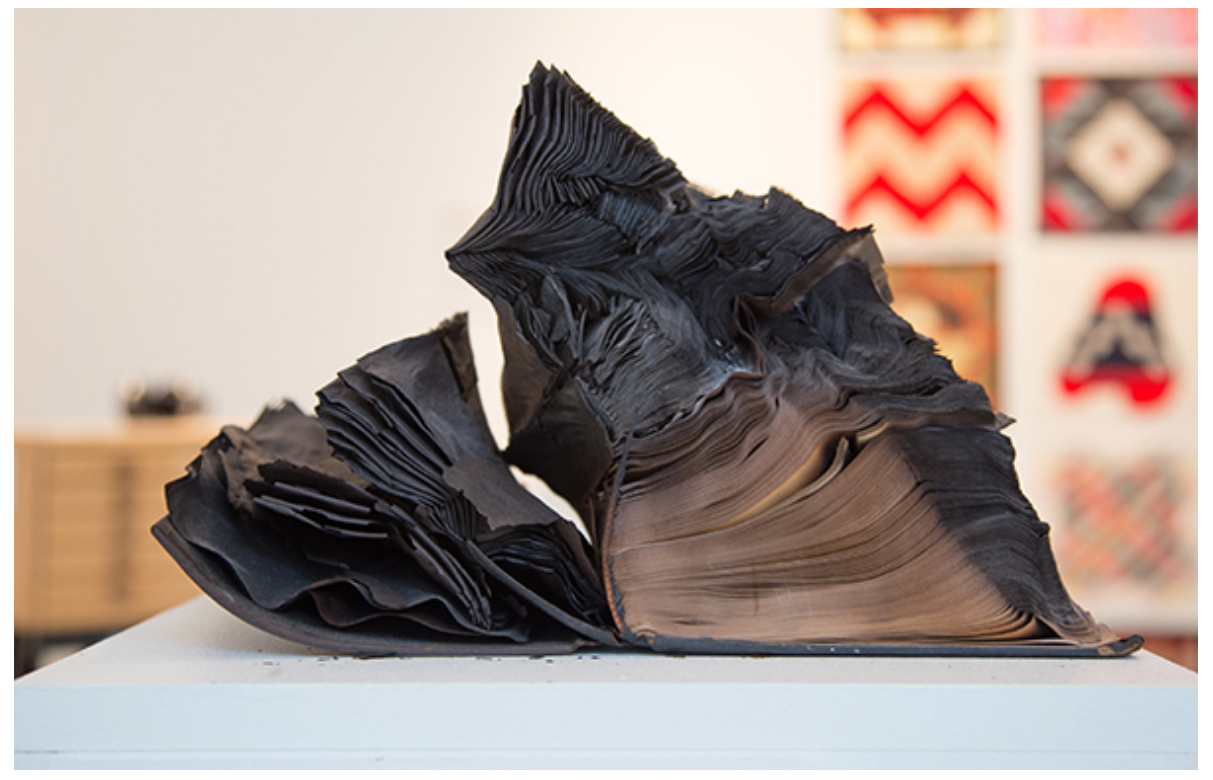

Ka'i' K'atun (2005)

Los libros quemados aparecen en la serie titulada Libros de la memoria de Beatriz Cortez. La serie retoma la exploración de la relación entre la memoria, los libros, los archivos, la censura. La artista presenta unos libros ordenados en los estantes, luego unos libros aislados, quemados y 
destruidos. Estos libros pueden referirse a la praxis de la autocensura comentada por Sabbatella en su reseña de La biblioteca roja (2018). En El Salvador también algunas personas optaron por eliminar o enterrar sus libros por pavor a ser identificados como revolucionarios. A la vez, estos libros remiten a los archivos escondidos de los militares, ahora objeto de un contencioso jurídico, y metafóricamente a la memoria negada. Los libros quemados, transformados en material inútil e inerte, materializan la destrucción de la memoria. En la instalación, los textos chamuscados muestran una textura que los devuelve a su procedencia originaria, los árboles, pero sin vida. Estos libros se parecen a pedazos de carbón vegetal.

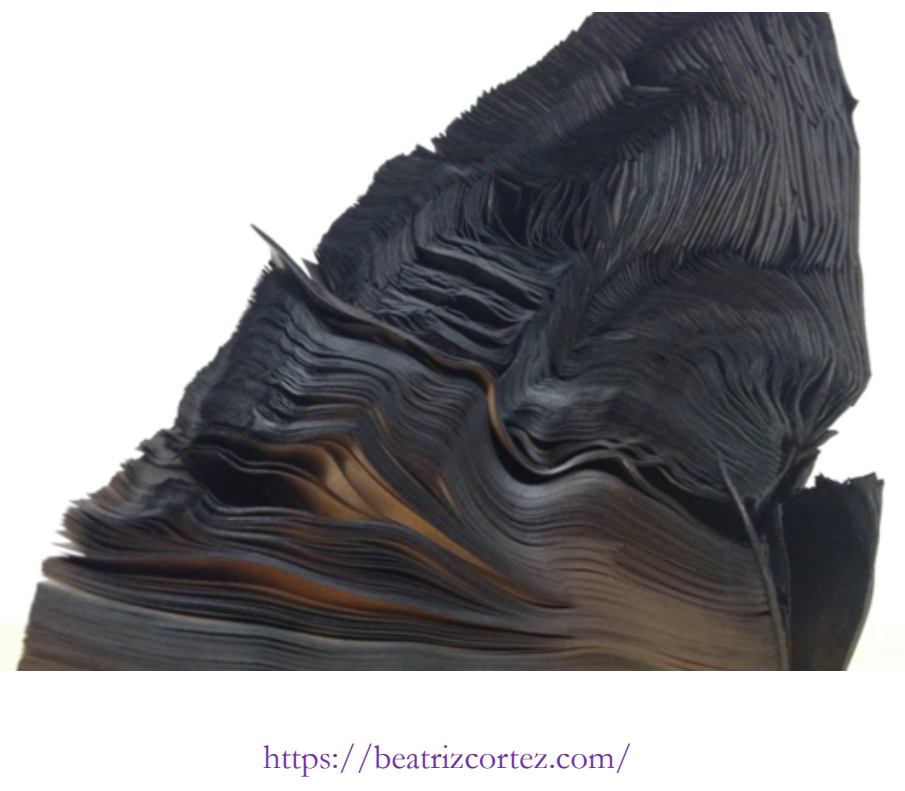

Sin embargo, al olvido y al sentido de pérdida comunicados por estos objetos, se agrega una esperanza. En los "libros jardín”, entre las páginas, Beatriz Cortez sembró unas semillas. Y luego empezaron a brotar unas plantitas. Sus raíces están metafóricamente arraigadas en las palabras, que se han convertido en objetos concretos capaces de hacer germinar la vida.

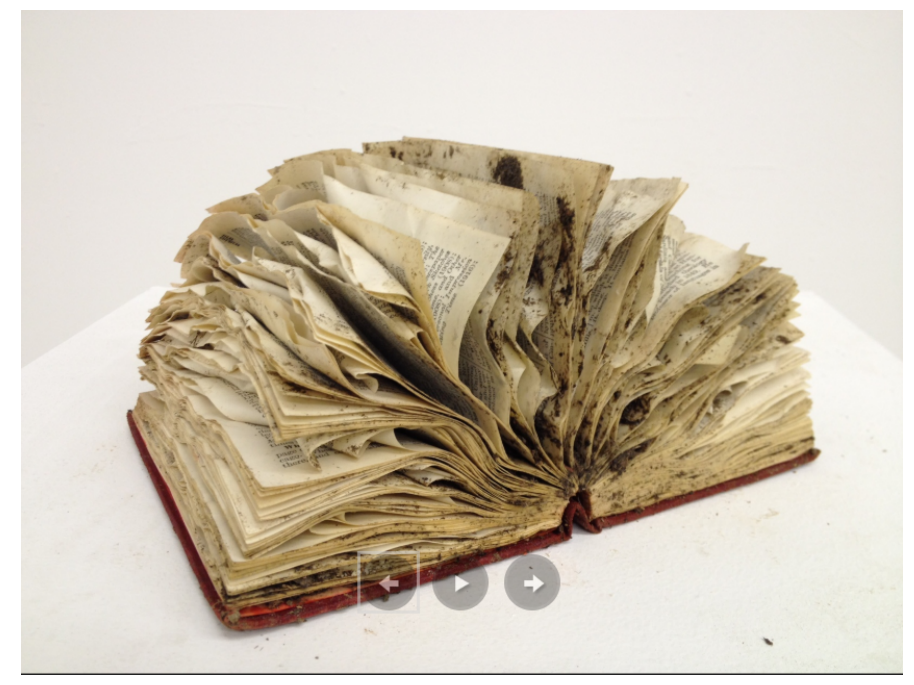

https://beatrizcortez.com/ 


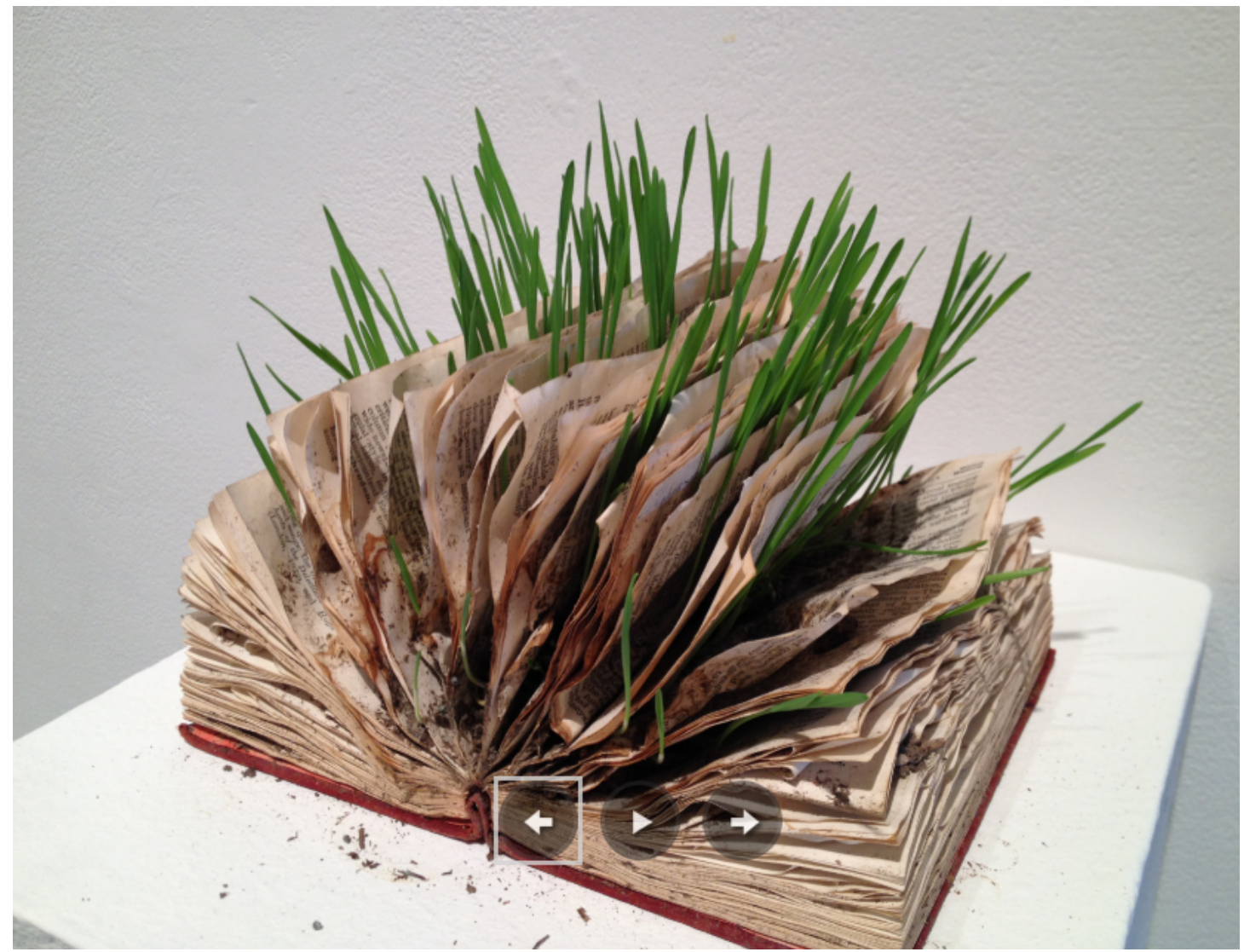

https://beatrizcortez.com/

La memoria es un proceso que se construye y en El Salvador hay artistas, escritores, historiadores que están creando una cultura de la memoria activa, que recuerda la injusticia sufrida y también la demanda de justicia que aún no se ha cumplido. Con la terquedad del izote.

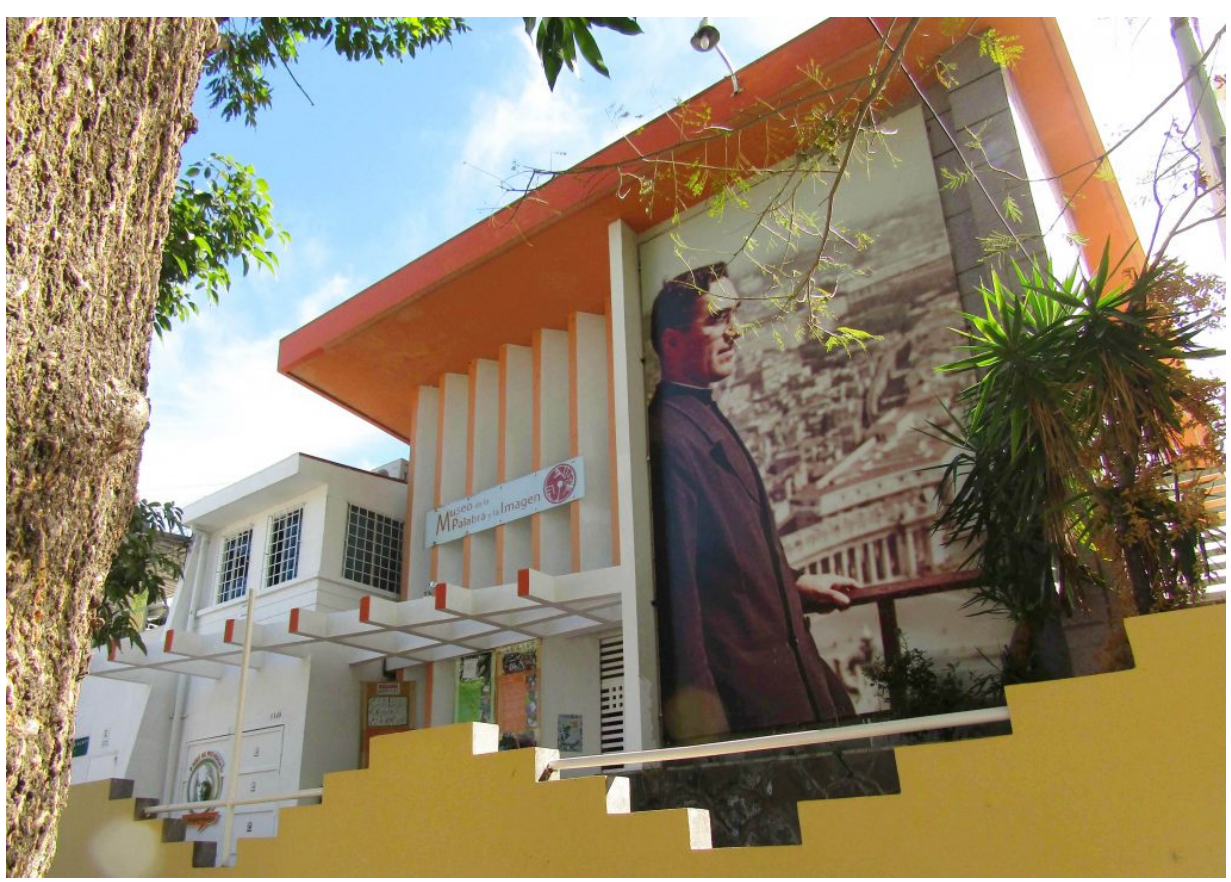

Museo de la Palabra y la Imagen, MUPI y el izote 


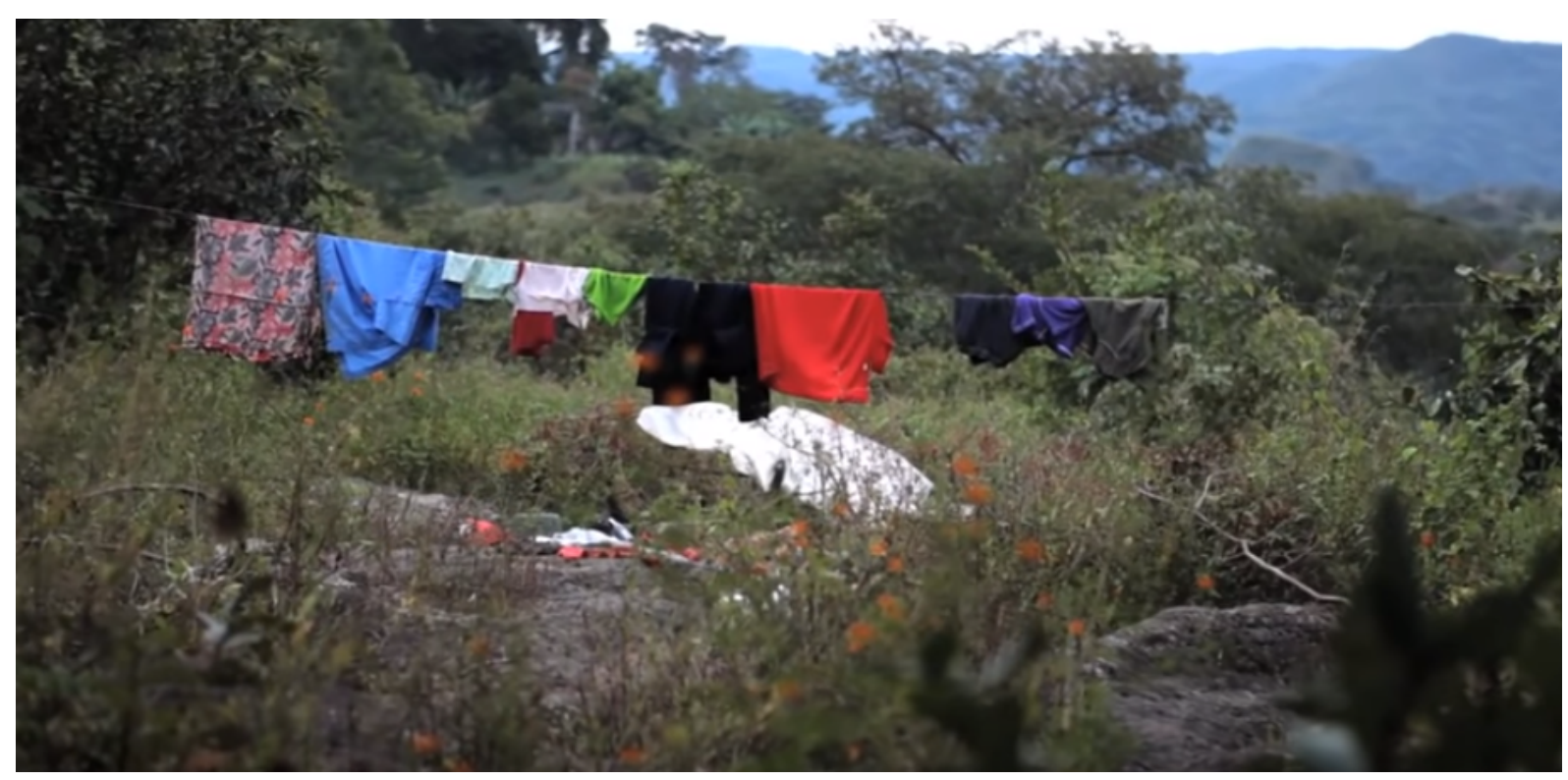




\section{BIBLIOGRAFÍA}

Agamben, Giorgio (2012). Quel che resta di Auschwitr. L'archivio e il testimone. Torino: Bollati Boringhieri.

AgAmBEn, Giorgio (2003). Stato d'eccezione. Torino: Bollati Boringhieri.

Alavarado, Moisés. "La clara mirada de Carmen Elena Trigueros". Séptimo sentido. (21 de octubre 2018).

Amaya Rufina, Danner Mark, Henríquez Consalvi Carlos (2014). Luciérnagas de El Mozote. San Salvador: Ediciones Museo de la Palabra y la Imagen.

Anderson, Thomas (2001). El Salvador, 1932. Los sucesos políticos. San Salvador: Dirección de Publicaciones e Impresos.

ARENDT, Hannah (1998). Los origenes del totalitarismo. Madrid: Taurus.

BAUDRILLARD, Jean (1978). Cultura y simulacro. Barcelona: Kairós.

BeLvedresi, Rosa E. "La teoría de Ricoeur sobre el reconocimiento: sus aplicaciones para la memoria y la historia". Páginas de filosofía 18 (2017): 9-28.

ButLer, Judith (2006). Vida precaria. El poder del duelo y la violencia. Buenos Aires: Paidós,

CANDELARIO, Sheila. "Patología de una insurrección: La prensa y la Matanza de 1932". Istmo: Revista virtual de estudios literarios y culturales centroamericanos 3 (2002).

Castellanos Moya, Horacio (2004). Insensater, Barcelona: Tusquets.

CAVArero, Adriana (2009). Horrorismo. Nombrando la violencia contemporánea. México: Anthropos.

CERRITOS Jorgelina (2017). 13703. El misterio de las utopias. San Salvador: Índole.

COMISIÓN DE LA VERDAD (2019). De la locura a la esperanza. La guerra de los 12 años en El Salvador. San Salvador: DPI.

CORTES, Beatriz (2012). "Los libros de la memoria”.

CORTES, Beatriz, "Amor por Rufina Amaya" (2014): https://beatrizcortez.com/armor-forrufina-amaya/

Dalton, Roque (1997). Miguel Mármol. Los sucesos de 1932 en El Salvador. San Salvador: UCA Editores.

Dalton, Roque (1999). Las historias probibidas del Pulgarcito. Madrid: Siglo XXI.

GARCíA MárQuEZ, Gabriel (2005). Cien años de soledad. Madrid: Cátedra.

GOULD, Jeffrey, LAURIA, Aldo (2008). 1932: Rebelión en la oscuridad. Revolución, represión y memoria en El Salvador. San Salvador: Ediciones Museo de la Palabra y la Imagen.

HalBWACHS, Maurice. "Espacio y memoria colectiva". Estudios sobre las Culturas Contemporáneas 9 (1990): págs. 11-40. 
Henríquez Consalvi Carlos "Santiago" (2012). La terquedad del izote. San Salvador: Ediciones Museo de la Palabra y la Imagen.

Henríquez Consalvi Carlos "Santiago" (2017). "Introducción”. SÁnCHEz CHICAS, Mercedes (ed.). Ventana a la memoria. Voces campesinas sobre el conflicto armado. San Salvador: Ediciones Museo de la Palabra y la Imagen, 9.

Hernández, Claudia (2007). De fronteras. Guatemala Editorial Piedra Santa.

JossA, Emanuela. "Cuerpos y espacios en los cuentos de Claudia Hernández. Decepción y resistencia”. Centroamericana 24 (2014): 5-37.

JossA, Emanuela. 'De la 'audiencia de los confines' a la 'audiencia de los márgenes'. El teatro de la memoria de Jorgelina Cerritos". Centroamericana 25 (2015): 71-95.

JossA, Emanuela. “- ¿Y qué pruebas tenemos ahora?- . El libro amarillo y 13703. El misterio de las utopias, tercer ensayo sobre la memoria de Jorgelina Cerritos”. Orillas 8 (2019): 455-568.

JOSSA, Emanuela. "Re-presentar la memoria: Regina José Galindo, Claudia Hernández, Jorgelina Cerritos". Istmo. Revista virtual de estudios literarios y culturales centroamericanos 38 (2019): 98-112.

JUANIZ MAYA José Ramón. "La experiencia del Tribunal Internacional para la Aplicación de la Justicia Restaurativa en El Salvador 2009-2015”. ECA Estudios Centroamericanos 740 (2015): 107-156.

KENEALY, Kate. “Una historia de mujeres". Trasmallo 4 (2009): 8-40.

LARA MARTíneZ, Rafael. "Del 32 como mito o la visión del vencido". Estudios Centroamericanos 463-464 (1987): 323-335.

MACKENBACH, Werner. "Realidad y ficción en el testimonio centroamericano". Istmo. Revista virtual de estudios literarios y culturales centroamericanos 2 (2001).

MEdRANO, Celia. "Bloquear el acceso a los archivos militares constituye desacato y complicidad". El Faro (11 de septiembre de 2020).

Museo de la Palabra y la Imagen, Mupi,

Ramos, Fred. “La vida interrumpida en El Mozote”. El Faro (8 de diciembre de 2017).

RAudA, Nelson. "Juez de El Mozote ordena a Bukele abrir los archivos militares de la masacre". ElFaro. (1 de noviembre 2019).

RAUDA, Nelson. "Juez de El Mozote a Presidencia: "Las decisiones judiciales no se negocian, se imponen”. El Faro. (31 de agosto 2020).

Ricoeur Paul (2004a). Tiempo y narración 1. Configuración del tiempo e el relato histórico. México: Fondo de cultura económica

RiCoeur Paul (2004b). La memoria, la historia, el olvido. México: Fondo de cultura económica.

Ricoeur Paul (2006). Caminos del reconocimiento. México. Fondo de cultura económica.

SABBATELla, Leonardo. "El libro como semilla de supervivencia”. Suplemento N, Clarín, (2018). 
SÁNCHEZ CHICAS, Mercedes (2017). Ventana a la memoria. Voces campesinas sobre el conflicto armado. San Salvador: Ediciones Museo de la Palabra y la Imagen.

SARlo Beatriz (2005). Tiempo pasado. Cultura de la memoria y giro subjetivo. Una discusión. Buenos Aires: Siglo XXI.

SonTAg, Susan (2003). Ante el dolor de los demás. Madrid: Santillana.

Trigueros, Carmen Elena (2014). "Lavandera”.

VÁSQUEZ Lucio (CHIYO). (2012). Siete gorriones: San Salvador: Ediciones Museo de la Palabra y la Imagen.

VÁsQUEZ RUIZ, Rolando. “Los sucesos de 1932: ¿Complot comunista, motín indígena o protesta subalterna? Una revisión historiográfica”. Revista Humanidades 3 (2014): 133-196.

VIDES, Verónica (2010). "La Barrida”.

YÚDICE, George. "Testimonio y concientización". Revista de crítica literaria latinoamericana. 18 (1992): 207-227. 